\title{
10 Evolutionary consequences of predation: avoidance, escape, reproduction, and diversification
}

\author{
R. Brian Langerhans \\ Department of Organismic and Evolutionary Biology, 26 Oxford St., \\ Harvard University, Cambridge, MA 02138, langerhans@oeb.harvard.edu
}

\subsection{Abstract}

One of the most important and obvious forces shaping organismal traits is predation. Prey have evolved diverse means of enhancing the probability of survival in the face of predation, and these means fall into two classes of antipredator strategies: (1) avoidance of predatory encounters, and (2) escaping after encountering a predator. A range of antipredator defensesincluding behavioral, morphological, physiological, and chemical defenses - serve to either reduce the probability of detection by a predator or enhance the probability of surviving after detection by a predator. However, the recognition that reproductive strategies (e.g. offspring number, reproductive lifespan) are typically strongly influenced by mortality regimes induced by predators, highlights that most but not all "antipredator traits" fall into one of these two categories - that is, some life history traits influence only fecundity, not survival. Life history evolution has not traditionally been included in reviews of antipredator adaptations, however this chapter reveals that the conceptual link between life histories and predation broadens and refines our understanding of predation's role in phenotype evolution.

While ecologists have long recognized the importance of predation in population- and community-level dynamics, a varied history exists for the study of predation's role in influencing evolutionary change. Despite the wealth of antipredator adaptations present in organisms, research investigating the significance of predation in biological evolution has received considerably less attention than other ecological factors (e.g. competition, mate attraction). However, predation can generate divergent selection among prey populations in several different ways, and is predicted to represent a major source of evolutionary change. Recent empirical work supports this claim. This chapter reviews the varied forms 
of evolutionary strategies prey have evolved to mitigate malicious attempts of natural predators, and the potential importance of predators in driving phenotypic divergence and speciation.

Keywords: Antipredator adaptations, divergent natural selection, fitness tradeoffs, life history evolution, phenotypic plasticity, predator-prey interactions, reproductive isolation, speciation.

\subsection{Introduction}

This chapter primarily examines classical predation in animals (i.e. consumption of one animal by another), however predation can be broadly defined to include all transfers of energy from one organism to another, including herbivores, parasites, parasitoids, and pathogens. To illustrate the generality of several concepts, examples will be provided from this more general definition of predation. Rather than offer an extensive review of antipredator strategies, this chapter highlights conceptual points meant to enhance our investigation and understanding of the role of predation in the evolution of prey traits.

The transfer of energy among organisms has long received considerable attention from ecologists (e.g. Elton 1927; Lindeman 1942; Huffaker 1958; Holling 1959; Paine 1966; Addicott 1974; Pimm 1982; Kerfoot and Sih 1987; Lima and Dill 1990; Polis and Winemiller 1996; de Ruiter et al. 2005). The importance of consumptive interactions in the distribution and abundance of organisms can be easily observed by a cursory glimpse of some important ecological concepts and terms: keystone predation, food web ecology, food-chain length, top-down effects, trophic cascade. While ecological consequences of predation have been firmly established, research into the role of predation in driving evolutionary change has lagged far behind studies centering on other ecological factors, such as resource competition (reviewed in Vamosi 2005). This is puzzling considering the vast array of antipredator adaptations present in extinct and extant organisms, the early attention predation received in the developing field of evolutionary biology (e.g. Müller 1879; Wallace 1879; Poulton 1890; Beddard 1892; Thayer 1896), and the repeated propositions that predation was likely a significant force of evolutionary change in need of more focused attention (e.g. Cott 1940; Worthington 1940; Fryer 1959; Askew 1961; Ehrlich and Raven 1964; McPhail 1969; Stanley 1979; Vermeij 1987; Schluter 2000). For more than a century, most evolutionarily oriented research investigating predation either examined 
fossil evidence - where predation has long enjoyed substantial respect as a driving force of evolutionary change (e.g. see chapters 2-3, 7-9, 13-15)or examined color patterns (i.e. crypsis, aposematism, mimicry) (see references in Komárek 1998; Ruxton et al. 2004). Outside of these two areas, evolutionary studies of predation have been comparatively minimal until a renewed focus began to emerge in the mid-1970s (e.g. Farr 1975; Gilbert 1975; Ricklefs and O'Rourke 1975; Holt 1977; Harvey and Greenwood 1978; Reznick and Endler 1982; reviewed in Vamosi 2005).

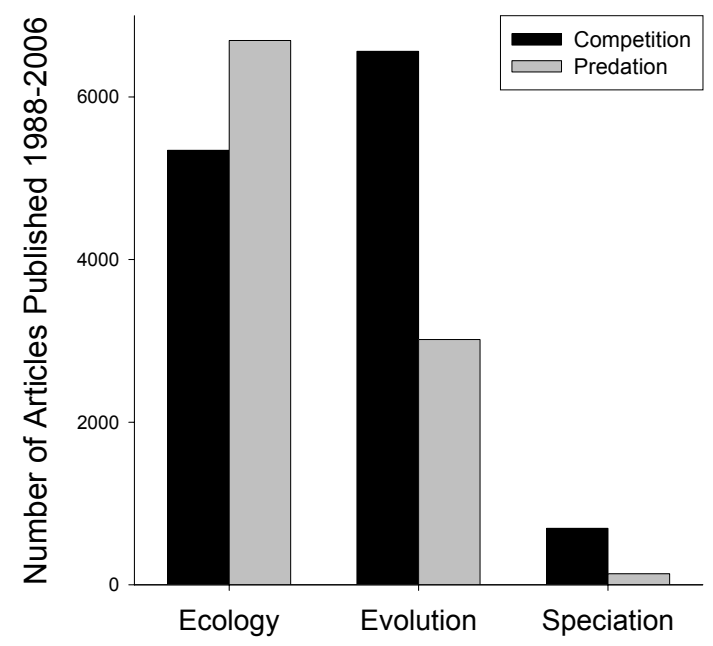

Fig. 1. Numbers of papers published in the general fields of ecology, evolution, and speciation involving the subjects of competition (black bars) and predation (grey bars). Data are from a search of the Institute for Scientific Information Science Citation Index conducted in March 2006. Searches included the following terms for each field of inquiry and subjects: Ecology = ecology, ecological, food web, population dynamic*, species distribution*, species abundance*, population distribution*, population abundance*; Evolution = evolution, evolutionary, diversification, divergence, differentiation; Speciation $=$ speciation, reproductive isolation, reproductive isolating, sexual isolation, sexual isolating; Competition = competition (excluding the terms predation and predator), Predation = predation, predator (excluding the term competition). Results are similar if "herbivory," "herbivore," and "herbivores" are included in the search for Predation, if the term "food web" is excluded from the search for Ecology, and if searches for one subject are not exclusive of the other factor (i.e. if the term "competition" were allowed in searches involving "predation" and vice versa)

To illustrate the disparity in the academic attention received by competition and predation among ecologically and evolutionarily oriented studies, I conducted a literature search compiling the number of recently 
published scientific articles involving either predation or competition in the general fields of ecology, evolution, and speciation. While predation receives considerable attention in ecological studies, it is clearly overshadowed by competition in evolutionary studies (Fig. 1).

During the temporal span of the search, the numbers of papers of a primarily ecological nature involving these two subjects is relatively similar $(\approx 25 \%$ more papers involving predation than those on competition); however, studies involving competition far outnumber studies involving predation for papers investigating evolution (more than twice as many) or speciation (more than 5 times as many). Thus, while it is widely recognized that predation is among the most important ecological factors structuring natural communities (e.g. Paine 1966; Addicott 1974; Jeffries and Lawton 1984; Kerfoot and Sih 1987; Holt and Lawton 1994; Wellborn et al. 1996; Jackson et al. 2001; Shurin and Allen 2001; Almany and Webster 2004), its potentially important role in phenotypic divergence, speciation, and diversification rates has only recently attracted significant attention (e.g. Reimchen 1994; Endler 1995; McPeek et al. 1996; Reznick et al. 1997; Blackledge et al. 2003; Langerhans et al. 2004; Nosil 2004; Vamosi and Schluter 2004; Vamosi 2005; Nosil and Crespi 2006b). Surprisingly, the extension of predation's importance in the distribution and abundance of species to its consequences for the distribution and abundance of phenotypes within and among species has been relatively slow in development. This chapter is meant to illustrate that when antipredator traits are reviewed with a broad, evolutionary perspective, the evidence overwhelmingly points to predation as a major force of evolutionary divergence across a wide range of phenotypes, and its role in speciation particularly demands future investigation.

\subsection{Solving the problem of being eaten: avoidance and escape}

Predation is a fundamental and pervasive component of ecosystems. Virtually every organism is perceived as a potential prey by some other organism. Obviously, an organism has little chance of reproducing and proliferating its lineage if it is severely injured or consumed by predators. Thus, selection has presumably strongly favored prey traits that increase the probability of survival and reproduction amidst predators. For the purposes of this chapter, "antipredator traits" are traits that predatormediated natural selection has played a role in shaping, although they may 
have a different function in some current populations and may be influenced by other factors as well.

Previous authors have described various conceptual frameworks for understanding antipredator traits (e.g. Edmunds 1974; Vermeij 1982; Sih 1987; Lima and Dill 1990; Endler 1991; Caro 2005). I believe the most natural approach perceives predator-prey interactions from a prey's perspective, and categorizes antipredator traits based on the manner in which the traits influence prey fitness (i.e. individual viability, offspring viability, individual fecundity) and the chronological sequence of the possible components of predatory encounters - from pre-detection through recognition, attack, capture, and consumption (Table 1). Antipredator traits are highly diverse, spanning behavior, morphology, physiology, chemistry, and life history (reviewed in Edmunds 1974; Janzen 1981; Kerfoot and Sih 1987; Vermeij 1987; Greene 1988; Caro 2005). The approach taken in this chapter builds upon those of Sih (1987), Endler (1991), and Caro (2005), in an attempt to provide a more unified framework for understanding all possible types of antipredator traits.

To enhance survivorship in the face of predation, prey have evolved two types of strategies: (1) avoidance of predatory encounters, and (2) escaping after encountering a predator. Predator avoidance is defined as a reduction in the probability of detection by a predator. Predator escape is defined as a reduction in the probability of consumption after detection by a predator. Prey have evolved an astounding arsenal of defenses to avoid and escape predation (see Table 1). Importantly, antipredator traits do not necessarily enhance individual survivorship with predators, but might rather influence offspring survivorship or individual fecundity. Prey generally exhibit numerous antipredator traits, and as Table 1 illustrates, traits can influence both avoidance and escape, as well as affect different aspects of fitness. Further, traits can impact other traits through various means (e.g. physiological, architectonical), and trait correlations might take on a number of different forms (e.g. codependence: where one trait is determined by another; complementation: where specific combinations of trait values are required to achieve a particular function; see DeWitt et al. 1999; DeWitt and Langerhans 2003). Prey can additionally employ different traits in different ecological contexts and at different developmental stages. For example, different antipredator strategies might be utilized during different life stages or ages (e.g. employ crypsis when in larval form, rapid retreat when adult). Thus, effects of predation on phenotype evolution can be quite complex. 
Table 1. Framework for understanding antipredator traits based on the manner in which traits directly influence prey fitness and the chronological stage of the predatory encounter in which they are employed. All prey traits are discussed in the text. Acronyms are as follows, ASF: avoiding a predator's sensory field, DSF: avoiding detection within a predator's sensory field, ATD: attack deterrence, CPD: capture deterrence, CND: consumption deterrence, $\mathrm{Y}$ : yes

\begin{tabular}{|c|c|c|c|c|c|}
\hline \multirow[b]{3}{*}{ Prey Trait } & \multicolumn{5}{|c|}{ How the Antipredator Trait Directly Enhances Fitness } \\
\hline & \multicolumn{2}{|c|}{ Increase Individual Survivorship } & \multicolumn{2}{|c|}{ Increase Offspring Survivorship } & \multirow[b]{2}{*}{ Increase Individual Fecundity } \\
\hline & Avoidance & Escape & Avoidance & Escape & \\
\hline Activity level & ASF & & & & \\
\hline Crypsis & DSF & & & & \\
\hline Development time & ASF & & & & \\
\hline Use predator-free habitat & ASF & & & & \\
\hline Active defense & & CPD, CND & & & \\
\hline Aposematism & & ATD & & & \\
\hline Attack diversion & & CPD & & & \\
\hline Autotomy & & CPD & & & \\
\hline Chemical defense & & ATD, CPD, CND & & & \\
\hline Death feigning & & ATD & & & \\
\hline Deimatic behavior & & ATD, CPD & & & \\
\hline Mimicry & & ATD & & & \\
\hline Protective morphologies & & ATD, CPD, CND & & & \\
\hline Rapid retreat, protean behavior & & CPD & & & \\
\hline Grouping & ASF, DSF & ATD, CPD, CND & & & \\
\hline Use protective habitat & ASF, DSF & ATD, CPD, CND & & & \\
\hline Vigilance & ASF, DSF & ATD, CPD, CND & & & \\
\hline Reproductive timing & & & ASF, DSF & ATD, CPD, CND & Y \\
\hline \multicolumn{6}{|l|}{ Reproductive effort: } \\
\hline -Offspring size & & & ASF, DSF & ATD, CPD, CND & \\
\hline -Parental care & & & ASF, DSF & ATD, CPD, CND & \\
\hline -Offspring number & & & ASF, DSF & ATD, CPD, CND & $\mathrm{Y}$ \\
\hline -Frequency of offspring production & & & & & Y \\
\hline -Reproductive lifespan & & & & & $\mathrm{Y}$ \\
\hline
\end{tabular}

The most important aspect of complexity involving antipredator traits is their likelihood of exhibiting tradeoffs with other aspects of performance. That is, their utility in defense against one predator might come at the detriment of defense against another predator, or the production of offspring, or the ability to acquire resources or mates. Such tradeoffs should generate divergent selection across environments differing in predator regime, and thus should be important in evolutionary divergence (see 10.7).

\subsection{Predator avoidance: winning without a fight}

Prey have evolved numerous means of reducing the probability of detection by a predator (see Table 1). These means can be divided into two categories: 1) avoiding a predator's sensory field, or 2) avoiding detection 
within the predator's sensory field. Prey remove themselves (and their offspring, see 10.6) from a predator's sensory field primarily by using habitat with decreased probability of predator presence, by reducing their activity level, and by reducing time spent in vulnerable life stages. Prey avoid detection within a predator's sensory field primarily through crypsis.

\subsubsection{Steering clear of a predator's realm: avoiding a predator's sensory field}

Many organisms have evolved means of avoiding contact with predators through their habitat use. Some prey live their entire lives, or spend much of their time, in holes, fissures, crevices, and other sheltered refugia (termed anachoresis). Others use ephemeral habitats that are too temporary in nature or too frequently disturbed to be available to predators, while others use stressful habitats that are too physically severe to allow persistence of predators (e.g. Edmunds 1974; Sih 1987). Prey might use these low-predation habitats exclusively, or might exhibit temporal habitat shifts, thus remaining active, but in different habitats at different times. Utilizing low-predation environments reduces the probability of a prey entering a predator's sensory field, however the use of more general protective habitats might also influence other aspects of predator avoidance and escape (see 10.5.4).

A common antipredator response of many animals is reduced activity level, where probability of detection is reduced by limiting activity to relatively safe situations and/or minimizing time available for detection. For instance, many organisms restrict activity to particular times of the day (e.g. nocturnal and crepuscular activity) or seasons (e.g. diapause, dormancy, cyst formation) (reviewed in Stein 1979; Hairston 1987; Stemberger and Gilbert 1987).

Timing of developmental schedules is an important, but underappreciated form of predator avoidance. Some organisms exhibit rapid growth during vulnerable life stages to quickly reach a less vulnerable stage, or inhibit growth into a vulnerable stage until a relatively safe time period (Williams 1966; Istock 1967; Wilbur 1980; Roff 1992). To date, most empirical research on this topic has centered on the influence of predation on the timing of hatching and metamorphosis in amphibians (e.g. Werner 1986; Sih and Moore 1993; Warkentin 1995; Chivers et al. 2001; Saenz et al. 2003; Vonesh 2005). A related, but distinct, topic is reproductive timing, which describes schedules of reproductive events (rather than growth rates or life-stage changes) and 
primarily affects aspects of fitness other than individual viability. That topic is discussed in section 10.6.1.

\subsubsection{Hiding in plain sight: avoiding detection within a predator's sensory field}

Crypsis, the phenomenon where an organism resembles a random sample of relevant aspects of its environment, is a highly important form of predator avoidance, and is found in many disparate taxa (reviewed in Cott 1940; Norris and Lowe 1964; Edmunds 1974; Endler 1978; Caro 2005). Crypticity is meant to reduce detection within the sensory field of a predator, and includes reduction of visual, tactile, chemical, and electrical detection. For example, Queen parrotfish (Scarus vetula) surround themselves at night with a transparent mucus cocoon. This cocoon greatly reduces odors emanated from the fish, hiding its scent from predators. Effectiveness of crypsis often depends on a prey's ability to remain still, move subtly, utilize appropriate background environments, and coordinate behaviors with appropriate changes in body coloration.

Classic examples of crypsis include remarkable cases of background matching by prey organisms (e.g. flat-tailed geckos, sargassum fish, transparent zooplankton), but crypsis also includes more simple cases of blending in with the background, such as disruptive coloration, barred color patterns, general color matching, and countershading. These less spectacular forms of crypsis are extremely common and often highly effective. Countershading is ubiquitous among many taxa (e.g. fish, mammals, birds) and helps break up the body outline by exhibiting darker coloration dorsally and paler coloration ventrally (obscuring the ventral shadow formed by overhead lighting which reveals the body form) (Thayer 1896; Poulton 1902; Cott 1940; Kiltie 1988; Ruxton et al. 2004). The survival advantage of crypsis has now been demonstrated in a number of taxa (e.g. Cott 1940; Dice 1947; Cain and Sheppard 1954; Kettlewell 1956; Edmunds 1974; Caro 2005), and results of early experiments on body color in fish and grasshoppers are presented in Fig. 2.

Some authors consider particular types of mimicry as special cases of crypsis, however I distinguish crypsis from mimicry by the occurrence of detection. That is, cryptic organisms avoid detection by predatorspredator avoidance - whereas organisms mimicking inedible organisms or objects allow detection, but avoid recognition as a palatable prey itempredator escape. Thus, mimicry is discussed below under the subject of predator escape. 


\subsection{Predator escape: prey fight back}

Many prey traits enhance the probability of survival despite detection by a predator. These traits can be divided into three categories based on three chronological components of a predatory encounter: 1) attack deterrence, 2) capture deterrence, and 3) consumption deterrence.

\subsubsection{Don't even think about it: attack deterrence}

Antipredator traits that comprise attack deterrence are those that reduce the probability that a predator will actually attempt an attack once detection has occurred. These traits are meant to advertise detection or quality in an attempt to stimulate the predator to withdraw. That is, prey produce signals that they have detected the predator and/or are of poor quality (i.e. difficult to capture, handle, digest, or altogether inedible).

A common method of attack deterrence is deimatic behavior. Deimatic behaviors alert a predator that it has been detected and are meant to frighten, confuse, or intimidate the predator. These behaviors often involve alarm calls in social animals that additionally serve to alert other prey individuals that a predator has been detected. In deimatic behavior, animals often attempt to appear strong, healthy, and large, and sometimes emit sounds, display bright colors (e.g. color flashes, revealing hidden areas of the body), eyespots, or weapons, and adopt a stereotypic posture (Edmunds 1974). Some animals even eject body fluids during deimatic behaviors, such as the blood squirting behavior of horned lizards, the spraying of anal gland fluids in skunks, and the fluid jets and sprays of many arthropods (Eisner and Meinwald 1966).

Body fluids ejected during deimatic displays might affect a predator's senses (e.g. obscure vision), cause harm (e.g. fluids that are toxic to the predator), or simply confuse the predator. Examples of deimatic behaviors include the stotting and leaping of gazelles, flashing of colors in many cephalopods, erection of brightly colored or eyespotted wings in stick insects, chelae displays in crabs, crayfish and scorpions, and the striking eyespot displays of the Brazilian toad Physalaemus nattereri.

Aposematism is an important means of deterring an attack, and is common in both plants and animals (e.g. Edmunds 1974; Bowers 1993; Komárek 1998; Mallet and Joron 1999; Lev-Yadun et al. 2002; Härlin and Härlin 2003). Aposematic organisms have dangerous attributes (e.g. painful weapons, foul tastes), and advertise this fact via characteristic colors, structures, or other signals. Bright colors (often red, yellow, or orange) and spines are common signals for aposematic prey. 
For aposematism to be advantageous, predators must either sample some prey and learn to avoid attacking those with particular warning signals, or possess an evolved avoidance response for prey with particular warning signals - both of these possibilities have been demonstrated in various taxa.

Mimicry is another way to deter an attack, and is often discussed as an offshoot of aposematism because many (but not all) cases of mimicry involve aposematic prey as the model. Müllerian mimicry describes the phenomenon where an unpalatable or otherwise dangerous prey species (the mimic) evolves a resemblance to another aposematic prey species (the model), benefiting from the fact that predators already avoid the model species (and thus, reciprocally benefiting the model species as well) (Müller 1879).

Examples of Müllerian mimics include several genera of wasps and bees, and many heliconiid butterflies. Batesian mimicry describes the same phenomenon, with the exception that the mimetic species is actually palatable (Bates 1862). Thus, Müllerian mimicry involves honest signals, while Batesian mimicry involves counterfeit signals. Examples of Batesian mimics include the beetle Clytus arietis and the hoverfly Helophilus hybridus which both resemble Vespula wasps (Mostler 1935).

Further, mimicry need not involve resemblance to aposematic organisms, but can involve resemblance to any dangerous or unpalatable object. For example, many organisms resemble inedible objects, such as leaves, twigs, and bird droppings, and still others resemble predators or competitors of their predator-and these represent cases of Batesian mimicry since the prey are truly edible (Cott 1940; Edmunds 1974; Bowers 1993; Brakefield et al. 1992; Wiklund and Tullberg 2004).

Prey appearing unpalatable due to their resemblance to particular organisms or objects avoid attack due to a recognition failure in the predator. That is, the predator can detect the prey, but it does not recognize the individual as a prey item.

A similar case involves detection by the predator, but a failure to initiate a killing response, despite the possibility of initial recognition as a prey item. This is typically accomplished by feigning death, termed thanatosis. This response is widespread in arthropods, reptiles, amphibians, birds, and mammals; classic examples include chickens, American opossums, and the African ground squirrel (e.g. Ewer 1966; Robinson 1969; Edmunds 1974; Greene 1988; Caro 2005). 

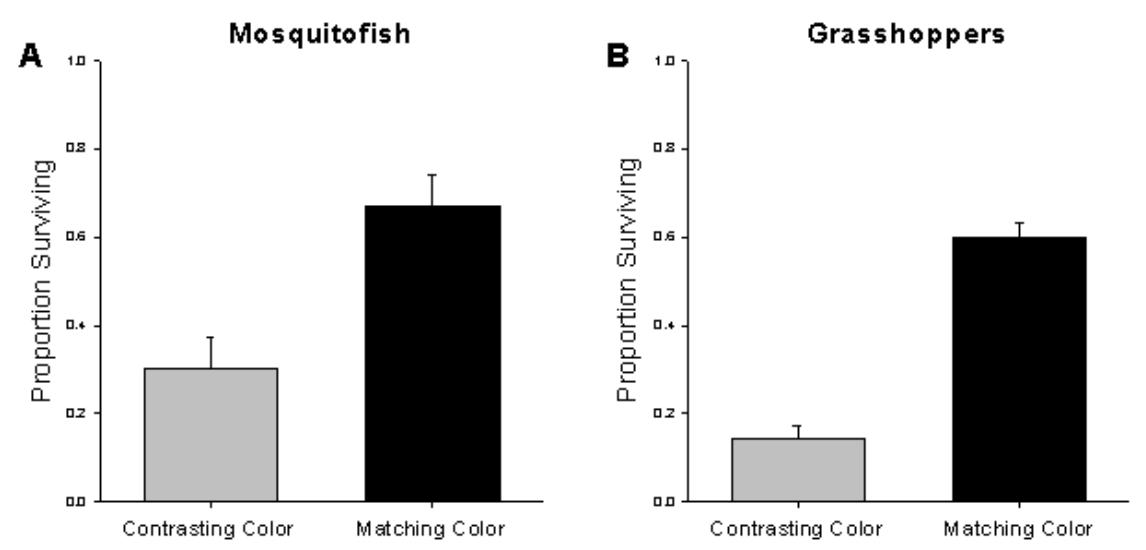

Fig. 2. Proportion of surviving prey individuals during experiments with predators exhibiting either a contrasting or matching body color with respect to its background environment. (A) Differential survival during predatory encounters with Galapagos penguins (Spheniscus mendiculus) for pale- and dark-bodied Western mosquitofish (Gambusia affinis) in pale and dark background environments (paired $t$-test, one-tailed $\mathrm{P}=0.0006$, eight experimental blocks, $\mathrm{N}=$ 1,046 fish; data from Sumner 1934). (B) Differential survival during predatory encounters with several bird species for several species of grasshoppers representing four color morphs in four corresponding background environments (paired $t$-test, one-tailed $\mathrm{P}<0.0001,25$ experimental blocks, $\mathrm{N}=758$ grasshoppers; data from Isley 1938)

In these cases, predators often lose interest in the prey and move away, or relax attention temporarily providing the prey an opportunity to retreat. In some cases of death feigning, prey might actually deter consumption, rather than attack, by stiffening the body in a position that operationally increases its size and thus reduces a gape-limited predator's ability to consume the prey (Honma et al. 2006).

\subsubsection{Catch me if you can: capture deterrence}

Once a prey has been attacked, it can reduce the probability of successful capture in several ways. One of the most widespread and common forms of capture deterrence is rapid retreat, where the organism attempts to quickly flee from the oncoming attack. To rapidly displace themselves from the predator, prey can run, jump, swim, fly, drop, or slither away. In some cases, the retreat may seem quite slow to the human observer, however it may still be adequate to escape the relevant predator (e.g. rapid retreats in many snails); thus "rapid" retreat is a relative term in reference 


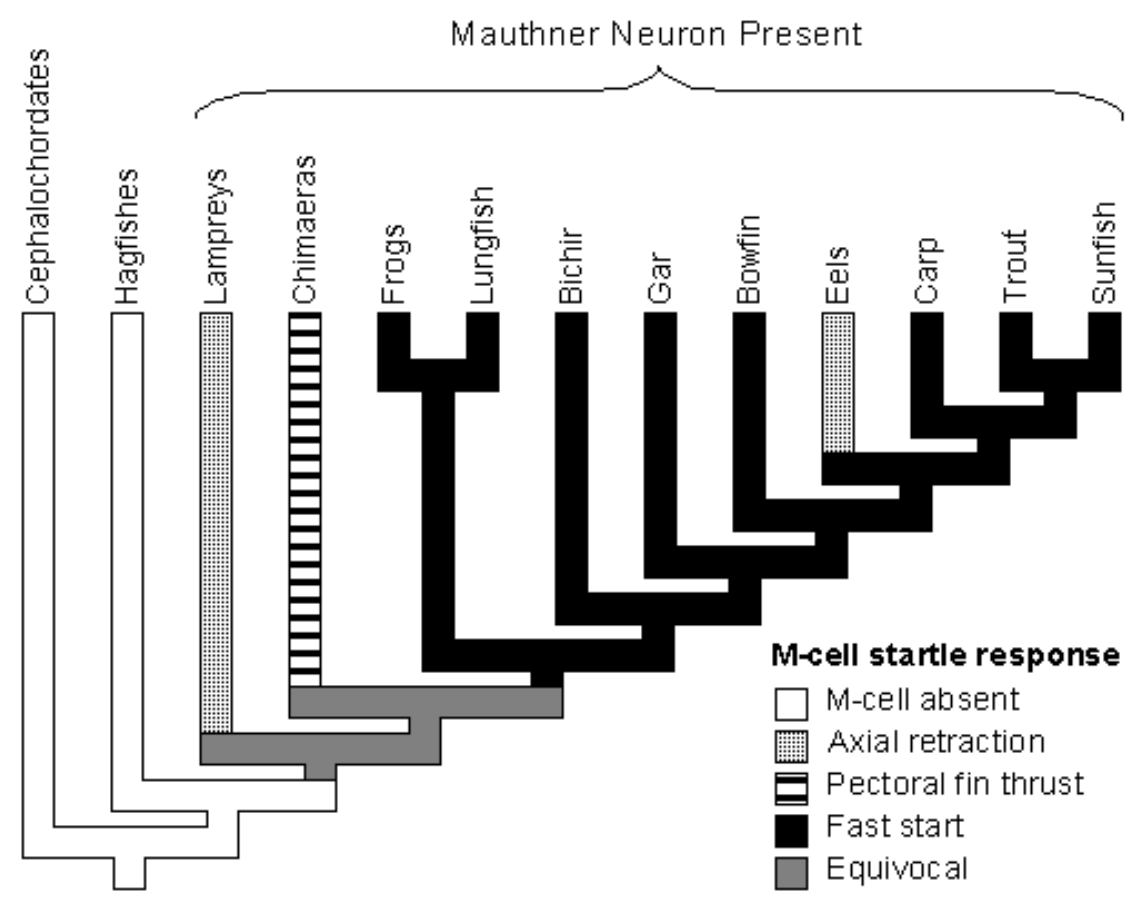

Fig. 3. Mauthner-cell initiated rapid retreats in chordates, illustrating the fundamental importance of predator escape responses. For frogs, Mauthner neurons produce a fast-start in tadpoles and elicit an escape jump in adults (Will 1986; Hoff and Wassersug 2000). Data from Hale et al. (2002)

to the speed of the oncoming attack. A classic example of rapid retreat is the Mauthner-cell initiated fast-start escape mechanism present in most anurans and fishes (Domenici and Blake 1997; Hale et al. 2002). This mode of rapid locomotion is highly important in surviving predatory strikes (Walker et al. 2005) and is conserved in general form across a wide range of organisms (Fig. 3). Rapid retreat is often combined with protean behavior, which describes irregular, unpredictable escape patterns and displays serving to confuse, disorient, and evade the predator (e.g. Humphries and Driver 1967; Humphries and Driver 1971; Edmunds 1974; Driver and Humphries 1988). For example, many prey flee from predators in an erratic, zigzagging, or bouncing fashion, or combine multiple behaviors in unpredictable manners. A highly studied predator-prey interaction involving rapid flight and strong protean behavior is the batmoth system (e.g. Roeder 1962; Roeder 1965; Acharya and Fenton 1992; Rydell et al. 1995; Waters 2003). Efficacy of rapid retreat can also be enhanced by close proximity to a refuge, contrasting coloration, the 
flashing of colors during the retreat, grouping behaviors, or ejection of body fluids, such as the smoke screen effect of ink ejection in many octopus and luminescent clouds in some squids (e.g. Edmunds 1974; Helfman et al. 1997; Brooke 1998; Caro 2005; Palleroni et al. 2005).

Many prey have evolved an attack diversion to reduce the probability of capture during an attack. That is, many prey exhibit "predator lures" which divert the attack of the predator to less vulnerable objects or regions of the body (e.g. Edmunds 1974; Caldwell 1982; Riley and Loxdale 1988; Van Buskirk et al. 2003). For example, some prey exhibit defection marks which direct attacks to nonessential or distasteful parts of the body, such as the false eyes and antenna of some butterflies, the false heads of some snakes, and conspicuously colored tails of some lizards. Autotomy, the ability to break off a part of the body when attacked, is a common mode of attack diversion in many organisms, and is often combined with deflection marks centered in these expendable body regions. In these cases, predators are left with only a small part of the prey, while the prey survives another day (e.g. lizard tails, mollusc papillae, arthropod limbs). A remarkable example of attack diversion is found in the cuttlefish, which sometimes ejects a cloud of dark, viscous ink. This ink remains as a discrete unit for some time, resembling the cuttlefish in general size and color; predators often attack this cloud while the cuttlefish pales in color and flees (Holmes 1940; Boycott 1958).

\subsubsection{Go ahead, try and eat me: consumption deterrence}

Even after a prey has been detected, attacked, and captured, there is still a chance for it to avoid consumption-and a number of antipredator adaptations represent consumption deterrence. Many organisms prevent consumption, and sometimes capture, through active defense, whereby organisms behaviorally interact with the predator using weapons evolved specifically for defensive purposes (e.g. claws, spines), as well as structures more commonly employed during food capture (e.g. teeth/jaws, stingers), intraspecific interactions (e.g. antlers, horns), and a range of other activities (e.g. limbs, hooves) (e.g. Edmunds 1974; Vermeij 1982; Caro 2005). In each of these cases, behavioral actions are taken by prey to reduce the efficiency of a predator's capture, handling, and consumption. Included in this category are the electric shocks produced by some fishes when seized. In some cases, active defense is aided by expulsions or secretions of the prey that are not necessarily noxious, but rather mechanically interfere with consumption. For example, physid snails sometimes deposit egg jelly and eggs on the feeding parts of attacking 
crayfish. This typically results in the crayfish predator dropping the snail to scrape clean the mouthparts and limbs, while the snail crawls away (DeWitt 1996; DeWitt et al. 2000).

Numerous prey have evolved protective morphologies that reduce the mechanical efficiency of consumption without requiring active deployment. Examples of protective morphologies include unwieldy size and shape, and defensive armor and spines; such defenses are common in both plants and animals (Edmunds 1974; Zaret 1980; Jeffries and Lawton 1984; Myers and Bazely 1991). While many of these morphologies enhance consumption deterrence, some may also affect attack deterrence (e.g. armor or spines can provide signals for aposematic prey) or capture deterrence (e.g. difficult to seize small or large prey).

Another common means of reducing the post-capture probability of consumption is chemical defense. Many organisms possess noxious chemicals, sometimes associated with weapons or protective morphologies, which are emetic, produce bad tastes, foul odors, or painful experiences for the predator. Noxious chemicals can also be used in other modes of predator escape (i.e. attack deterrence, capture deterrence), however they are often employed as a method of last resort. For instance, many organisms have chemical defenses only released after capture or injury. One example of highly toxic prey are newts; some of which can actually be swallowed, their toxins eventually killing the predator, and then safely emerge from the dead predator's mouth (Brodie 1968; Hanifin et al. 1999). Chemical defenses are also very common in plants (e.g. Karban and Baldwin 1997; Agrawal et al. 1999; Tollrian and Harvell 1999). An alternative strategy to the inhibition of consumption is to actually pass safely through the predator's gut; this phenomenon typically involves chemical defenses and has been described in some plants and invertebrates (e.g. Vinyard 1979; Aarnio and Bonsdorff 1997).

\subsubsection{Multitasking prey: all-purpose antipredator traits}

Some antipredator traits have the potential to influence all chronological stages of predator-prey encounters. For example, predator detection (vigilance) can affect survivorship in a number of ways. Many prey, but not all, have evolved the ability to recognize their predators (reviewed in Caro 2005). Predator recognition is a fundamental prerequisite of vigilance. That is, only prey that possess the capability of distinguishing between predators and nonpredators can be vigilant, or employ activities to see, smell, hear, or chemically or electrically detect predators. Because this definition of vigilance is conceptual in focus (describing actions prey take 
to detect predators), it is broader than what is often operationally used in vigilance studies (e.g. when measuring vigilance it is often difficult to discern whether prey organisms are listening for predators while foraging). Many organisms utilize environments where predators occasionally occur, and use vigilance to increase the probability of detecting the predator before being detected themselves. Once a prey detects a predator, it can then perform a variety of subsequent actions to avoid or escape predation. For instance, vigilant prey often remain near a refuge so that when a predator is detected, they can quickly seek refuge until the predator threat has passed (all the while going unnoticed by the predator). One striking example of prey vigilance is the ability of many moths to the detect ultrasonic echolocation calls of bat predators - an ability that has apparently evolved at least six separate times and increases survival through early detection (e.g. Treat 1955; Roeder 1962; Hoy et al. 1989; Yack and Fullard 2000; Waters 2003). While vigilance can enhance survivorship, it can also suffer costs, such as lost time or energy that could have been used for other important activities (e.g. Brown 1999; GauthierClerc et al. 1998; Caro 2005).

Many prey use protective habitats to avoid or escape predation. In these cases, prey utilize microhabitats that offer protection from predators in the form of a complex, structured setting, or an otherwise dangerous or impenetrable environment for the predator (e.g. shells of hermit crabs). Protective habitats can enhance prey survivorship in many ways. For instance, many aquatic organisms inhabit complex habitats such as macrophytic vegetation and coral reefs, and some plants and invertebrates live in close association with plants exhibiting high levels of antiherbivore defenses, such as cactus or chemically-defended seaweeds. These environments can hide prey, obscure prey, cause predators to halt their attacks, cause difficulty in negotiating prey capture, and reduce the ability of a predator to successfully consume and digest prey. Many animals temporarily utilize stressful environments that predators have difficulty penetrating, such as low-oxygen or high-temperature aquatic microhabitats. One striking example of the use of such protective habitats is the finding that many fish species that were presumed extinct subsequent to introduction of predatory Nile perch (Lates niloticus) in East African lakes have actually persisted in the swampy fringes of the lakes, where structural complexity and hypoxic conditions reduce detection and capture abilities of the predator (Chapman et al. 1996a; Chapman et al. 1996b; Chapman et al. 2002).

Conspecific or multispecies grouping behaviors (e.g. flocking, herding, schooling) can affect survivorship in a number of ways, and have received considerable research (e.g. Hamilton 1971; Vine 1971; Morgan and Godin 
1985; reviewed in Caro 2005). In one type of grouping behavior, prey associate themselves with organisms that predators avoid (i.e. the enemy of my enemy is my friend), thus reducing the probability of entering a predator's sensory field. Many prey often aggregate with other organisms within a predator's sensory field, where individual prey within the group reduce their probability of being detected by a predator; although the group itself might be more easily detected than an individual. One advantage of grouping that has been long discussed is the increase in vigilance efficiency, as groups often detect predators earlier, even though each individual may spend less time being vigilant when in groups (e.g. Darwin 1871; Galton 1871; Miller 1922; Pulliam 1973; Kenward 1978; Trehorne and Foster 1980). Efficacy of deimatic behaviors can also sometimes be improved by grouping behaviors (Edmunds 1974; Humphries and Driver 1967). Further, grouping behaviors can reduce the probability of an attack through a dilution effect (e.g. Hamilton 1971; Bertram 1978; Viscido et al. 2001). By grouping, individuals reduce their probability of being attacked by effectively diverting attacks to other members of the group. Grouping can also increase the efficacy of rapid retreat (e.g. Miller 1922; Welty 1934), as well as active defense (e.g. Edmunds 1974; Pulliam and Caraco 1984).

\subsection{Reproductive strategies: transcending predators through life history traits}

Most antipredator traits increase fitness amidst predation by increasing individual survivorship (all those described above). However, predatormediated selection can also favor traits that do not necessarily affect individual survivorship, but rather serve to increase offspring survivorship or individual reproductive output (Roff 2002). Increasing any of these three factors (i.e. individual survival, offspring survival, individual fecundity) can enhance fitness in a predatory environment by augmenting lineage proliferation. While many antipredator traits can indirectly increase fecundity by increasing viability - and thus, a prey's ability to produce offspring - there are some traits that actually influence fecundity directly. In this section, I discuss traits that directly influence offspring survival and/or individual fecundity, and refer to these as life history traits. Traits influencing offspring survivorship (i.e. reproductive timing, parental care, offspring size, offspring number) either enhance predator avoidance or escape, while traits only influencing fecundity (i.e. frequency of offspring production, reproductive lifespan) do not. 


\subsubsection{Know when to hold 'em, know when to fold 'em: reproductive timing}

Predator-induced mortality regimes can favor particular reproductive schedules (e.g. early vs. late sexual maturity) that enhance individual fecundity (e.g. Stearns and Crandall 1981; Mangel and Clark 1988; Crowl and Covich 1990; Reznick et al. 1990; Roff 2002). Prey organisms can further enhance fitness in the face of predation by timing reproductive events (e.g. mating, fertilization, pregnancy, birthing) to correspond with time periods where offspring might enjoy relatively high survivorship. Such adjustments in reproductive timing can increase the offspring's probability of either avoiding or escaping predators. For example, prey might produce offspring at a time when the level of crypsis is elevated, when predators exhibit low densities or are absent, when predators are weak or otherwise more vulnerable to prey defenses, or when environmental conditions reduce a predator's prey capturing abilities. To date, few studies have examined shifts in reproductive timing in response to predator-induced mortality, although a number of examples are known for the effects of abiotic sources of mortality (e.g. desiccation, reduced energy sources due to winter; Thomson 1950; Lack 1954; Newman 1988; Brinkhof et al. 1993; Van Noordwijk et al. 1995; Reznick et al. 2006b). Reproductive timing can also influence individual viability by minimizing negative effects of offspring production (e.g. pregnancy, egg production) on capture deterrence. That is, prey are often more easily captured during reproductive events, and thus the timing of these events can be selected to avoid major individual fitness costs.

\subsubsection{Putting all your eggs in one basket and flooding the market: reproductive effort}

The reproductive effort of an organism describes the allocation of energy towards reproduction during its lifespan. This includes several important life history attributes that can be influenced by predator-induced mortality regimes. Because many prey populations experience unsaturated environments (i.e. few limiting resources) under high predation levels, they are generally believed to be $r$-selected (i.e. density-independent selection maximizing per capita population growth rate) in the classic $r-K$ continuum of life history theory (MacArthur 1962; MacArthur and Wilson 1967). Thus, prey species often exhibit reproductive strategies reflecting a maximization of lineage growth rate. Here, I discuss how reproductive effort, and components thereof, might be shaped by predation. 
To maximize lineage growth, life history theory generally predicts the evolution (or induction) of increased reproductive effort under high predation pressure (Kozlowski and Uchmanski 1987; Abrams and Rowe 1996; Roff 2002). Parental care can be thought of as synonymous with reproductive effort as defined here, and includes all supply of energy towards reproduction. Many prey organisms employ high levels of parental care to enhance fecundity amidst predators. For example, prey can protect and provide nutrients for embryos and juveniles through nest site selection, nest morphology, active defense of offspring, and production of yolk, endosperm, and a placenta. Parental care of juveniles increases offspring survivorship by enhancing predator avoidance and escape (e.g. hiding offspring from predators, diverting predator attention from offspring, active defense of offspring from predators).

While predation may generally favor increased reproductive effort, the manner in which this effort is allocated can vary. For instance, an individual can produce one large offspring or several small offspring with equivalent levels of reproductive effort. Let us now consider how predation might influence offspring number and size.

The number of offspring per reproductive bout, or clutch size, can be selected to maximize lineage growth in response to predation. Such an optimization of clutch size can increase fecundity without altering offspring survival. In this scenario, offspring survivorship can be held constant, and the clutch size leading to the greatest lineage growth rate will be selected. Clutch size can also enhance predator escape ability for offspring. First, a low clutch size might ensure little competition among progeny and thus result in good health (which might often increase escape ability). Second, a high clutch size can provide an indirect form of attack deterrence by flooding the environment with offspring. In this situation, higher numbers of juveniles can result in a lower per capita probability of an attack. A striking example of this phenomenon is reproductive synchrony (or emergence/metamorphosis synchrony), where high clutch sizes may be combined with a developmental timing strategy to produce very high densities of juveniles, effectively reducing individual attack probabilities, and possibly gaining other advantages of grouping (e.g. mast seeding in oaks, periodical cicadas; Darling 1938; Lloyd and Dybas 1966; Hamilton 1971; Janzen 1981; Gochfeld 1982; Ims 1990; DeVito et al. 1998).

Offspring size — including embryo size, egg size, birth size, emergence size, hatching size, seed size - can influence both predator avoidance and escape. Thus, many prey organisms have evolved offspring sizes that enhance their survival in the presence of predators (e.g. Lloyd 1987; Janzen et al. 2000; Moran and Emlet 2001). For example, small offspring 
are often difficult to detect, while large offspring are often difficult to capture or consume. Offspring size is often correlated with offspring number, and thus will often evolve in a coordinated fashion (see discussion of trait correlations below).

Two additional components of reproductive effort that might often reflect the selective influence of predation are reproductive lifespan and frequency of offspring production (Roff 2002). These two traits can serve to increase individual fecundity in the face of predation. For example, prey organisms might exhibit a long reproductive lifespan (i.e. early age at maturity, late onset of senescence) and/or frequent production of offspring. These strategies can maximize fecundity in an environment with high levels of mortality. For example, Reznick et al. (2006a) found that guppies (Poecilia reticulata) that evolved with predators exhibit a longer reproductive lifespan than guppies that evolved in the absence of major fish predators. Further, Hubbs (1996) demonstrated that mosquitofish species (genus Gambusia) inhabiting relatively low-predation environments exhibit longer interbrood intervals. While strategies such as exhibiting many, frequent bouts of reproduction can sometimes decrease individual survivorship (e.g. mating, pregnancy, and parental care might increase vulnerability to predation), these strategies may still be favored as they can produce a net increase in fitness.

\subsection{Predators spawn phenotypic diversity of prey: plasticity, divergence, and speciation}

Effects of predators on prey phenotypes can be complex. Phenotypes generally reflect the influence of multiple selective agents in addition to predators. Predation can influence phenotypic values both directly, through predator-mediated selection, and also indirectly through trait correlations and interactions with other selective agents (e.g. Gould and Lewontin 1979; Lande and Arnold 1983; Sih 1987; Koehl 1996; Pigliucci and Preston 2004). Most prey exhibit numerous types of antipredator traits, and correlations among these and other traits are ubiquitous for several reasons (e.g. physiological, architectonical, functional, or developmental causes). Thus, effects of predators on one trait can indirectly influence other traits which are not under selection via predation. In natural systems, predators might also often affect the selective regime of prey by altering their interactions with other selective agents, such as altering levels of competition or densities of other predators. Because of this potential for complex networks of direct and indirect effects of environmental factors 
(e.g. predation) on traits, researchers must employ a pluralistic approach assessing both direct and indirect effects of multiple environmental factors on multiple phenotypes to gain a thorough understanding of how predation influences prey evolution (DeWitt and Langerhans, 2003; Schaack and Chapman, 2003; Caumul and Polly, 2005; Hoverman et al. 2005).

Many traits exhibit tradeoffs, where a given trait value increases fitness in one respect, but decreases fitness in another. Such tradeoffs are common among antipredator traits and non-defensive traits alike. For example, reduced activity level might reduce foraging opportunities, morphological and chemical defenses can be energetically costly and reduce fecundity, capability for high-speed movement might reduce sustained locomotion capabilities, grouping behaviors might lead to increased competition, defenses against one predator might increase vulnerability to another, and sexually selected ornamental traits can increase susceptibility to predation (e.g. Sih 1987; Lima and Dill 1990; Andersson 1994; McCollum and Van Buskirk 1996; Rigby and Jokela 2000; Reimchen and Nosil 2002; Vamosi 2002; DeWitt and Langerhans 2003; Ghalambor et al. 2004; Caro 2005; Langerhans et al. 2005).

Predators can drive phenotypic differences between prey populations via several different mechanisms, and tradeoffs are not prerequisites for divergence. Three common ways that predators can drive divergence of prey are: fitness tradeoffs in prey traits across different predator regimes (Fig. 4A), competition for "enemy-free space" (Fig. 4B), and predators altering interactions of prey with other selective agents (Fig. 4C). The first case stems from tradeoffs, while the latter two mechanisms of divergence need not involve such tradeoffs. The common thread among all modes of divergence is that divergent selection-selection pulling trait means of different populations toward different adaptive peaks - is responsible for phenotypic differences in each case (Fig. 4D). Phenotypic differentiation can result from environmentally contingent (i.e. phenotypic plasticity) or environmentally independent phenotype production.

\subsubsection{To induce or not to induce: tradeoffs can drive predator- induced plasticity}

Many prey organisms have evolved adaptive predator-induced phenotypic plasticity, where particular phenotypes are only produced under the threat of predation, thus avoiding fitness costs in the absence of particular predators. Other organisms (and sometimes other populations of the same species) have instead evolved fixed phenotypes, and exhibit constitutive defenses against predators. Whether plasticity or fixed phenotype 
production evolves largely depends on the spatial and temporal variability of predation, and the ability to predict future predation levels. Plasticity will typically be favored in a fluctuating environment where the environmental state can be accurately predicted using environmental cues, while fixed phenotype production will typically be favored when the predator regime is constant and costs associated with plasticity and information acquisition are relatively high (e.g. Bradshaw 1965; Levins 1968; Scheiner 1993; Gotthard and Nylin 1995; DeWitt and Langerhans 2004).

The importance of predators in adaptive plasticity of prey has received considerable attention during the past two decades. Predator-induced defenses in animals and herbivore-induced defenses in plants are very common (reviewed in Havel 1987; Karban and Baldwin 1997; Chivers and Smith 1998; Agrawal et al. 1999; Tollrian and Harvell 1999). An obvious form of predator-induced plasticity is the widespread occurrence of predator-induced antipredator behaviors in animals (e.g. Sih 1987; Lima and Dill 1990; Werner and Anholt 1993). Induced morphologies, life histories, and chemical defenses also now appear common in many taxa (e.g. Dodson 1989; Karban and Baldwin 1997; Agrawal et al. 1999; Tollrian and Harvell 1999; Pigliucci 2001; DeWitt and Scheiner 2004). For example, some animals induce defensive morphologies such as unwieldy body shapes or spines in the presence of predators, some animals induce egg hatching in response to a nearby predatory attack, and many plants induce chemical defenses when herbivores initiate an attack. Such plastic responses to predation represent important and widespread evolutionary consequences of predation, however plasticity's influence on diversification rates is largely unknown. The role of plasticity as a catalyst for subsequent evolutionary divergence and speciation, and its role as an inhibitor of extinction, is now receiving considerable attention (WestEberhard 1989; Schlichting and Pigliucci 1998; Pigliucci 2001; Robinson and Parsons 2002; Pigliucci and Murren 2003; Price et al. 2003; WestEberhard 2003; Schlichting 2004).

\subsubsection{Divergent selection between predator regimes: evolutionary divergence among prey}

Performance tradeoffs can also drive evolutionary divergence among prey populations, rather than favor phenotypic plasticity. Because predation is heterogeneously distributed across space and time, and because many traits exhibit tradeoffs across predatory environments, divergent selection on prey traits across predator regimes may be very common in nature. 
A

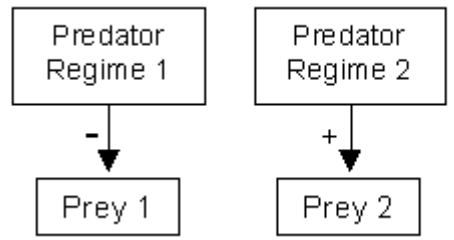

B

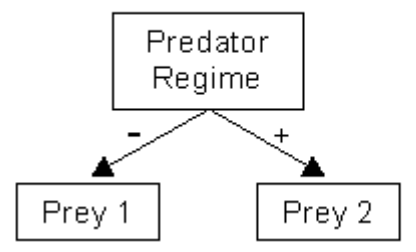

C

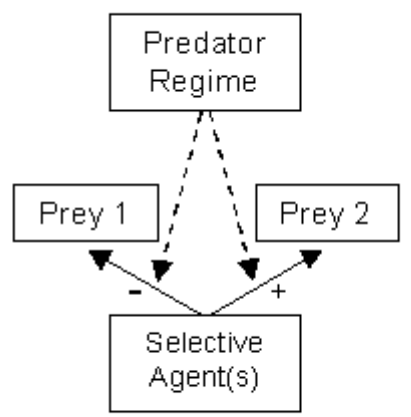

D

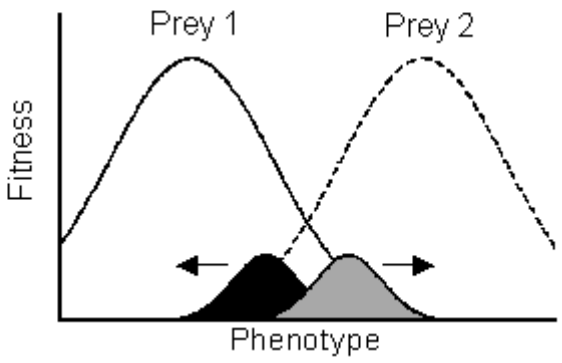

Fig. 4. Three common ways in which predators can drive phenotypic divergence among prey populations (or species). Solid arrows in A-C depict selection on a prey trait. The sign beside each arrow indicates the direction of the optimal phenotype in relation to the population mean. Divergent selection arising from (A) divergent predator regimes, (B) competition for enemy free space within a given predator regime, and $(\mathrm{C})$ an interaction between predation and the prey's selective regime. (D) Hypothetical fitness functions resulting from each scenario depicted in A-C, with trait distributions for the two prey populations represented by the shaded areas. Arrows in D illustrate the direction selection is pulling trait means for each population 
Empirical support for this proposition is growing (e.g. Reimchen 1994; McPeek 1995; McPeek et al. 1996; Reznick 1996; Reznick et al. 1997; Walker 1997; Conover and Munch 2002; Relyea 2002; Vamosi 2002; Vamosi and Schluter 2002; Langerhans et al. 2004; Reimchen and Nosil 2004; Vamosi and Schluter 2004; Langerhans et al. 2005).

One tradeoff that might be common in many organisms is the conflict between rapid bursts of movement (often important in capture deterrence) and endurance (often important for other essential activities, such as foraging) (e.g. Dohm et al. 1996; Reidy et al. 2000; Vanhooydonck et al. 2001; Wilson et al. 2002; Domenici 2003; Blake 2004). Aquatic organisms with coupled locomotor systems (i.e. using the same structures for more than one swimming mode), are predicted to generally experience a tradeoff between fast-start swimming performance and prolonged swimming performance, as these tasks require opposite suites of morphological and physiological traits. Specifically, a shallow anterior region and a deep caudal region are required to produce rapid fast-starts - a very important escape mechanism in most fishes and anurans (see Fig. 3) - however a deep anterior region and a shallow caudal region are required to optimize prolonged swimming performance - important for acquiring resources and mates (e.g. Blake 1983; Webb 1984; Webb 1986; Videler 1993; Vogel 1994; Walker 1997; Blake 2004). While the relationship between morphology and swimming performance can be complicated, this general tradeoff has been empirically confirmed when comparing across distantly related, morphologically disparate taxa (e.g. "accelerators" vs. "cruisers"), as well as within species (Reidy et al. 2000; Fig. 5). This tradeoff is predicted to generate divergent selection across low- and high-predation environments for prey populations. Recent empirical work supports this hypothesis, as a number of aquatic organisms have been found to exhibit the predicted morphological differences between populations (and species) inhabiting such divergent predator regimes (Walker 1997; Walker and Bell 2000; Langerhans and DeWitt 2004; Langerhans et al. 2004; Dayton et al. 2005).

In many cases, phenotypic divergence between predator regimes involves a suite of traits, rather than simply one form of capture deterrence. For example, many studies have investigated phenotypic differences between predatory environments (e.g. low vs. high levels of predation from predatory fish) in livebearing fish, particularly the Trinidadian guppy.

This work has revealed that divergent selection across predator regimes can drive the simultaneous divergence of a large number of traits, and livebearing fishes have become a model system to investigate predatordriven evolution. 


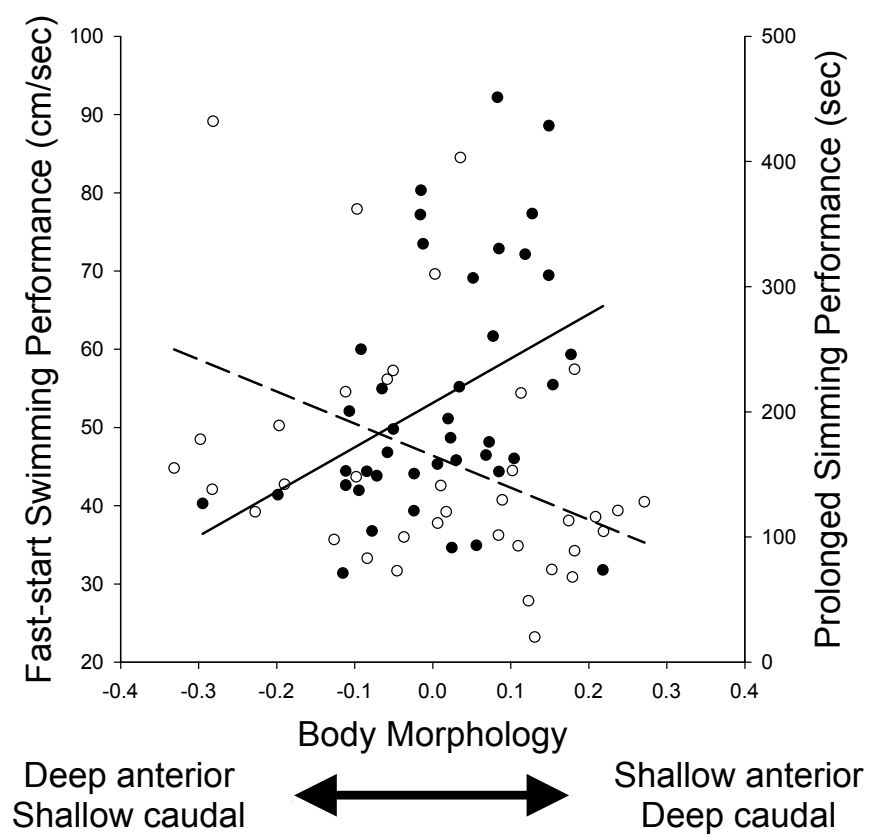

Fig. 5. Swimming performance tradeoff for body shape in male western mosquitofish (Gambusia affinis). Body shape represented by a canonical axis describing fish with a relatively deep anterior/head region and shallow caudal peduncle region at the negative end of the axis, and fish with an opposite morphology at the positive end. Solid line and filled symbols: fast-start swimming performance $(\mathrm{P}=0.006)$; dashed line and open symbols: prolonged swimming performance ( $(\mathrm{P}=0.007)$. Data from Langerhans et al. (2004) and RB Langerhans, MC Belk, and TJ DeWitt (unpublished data)

Guppies exhibit striking differences between predator regimes in body color, body shape, swimming performance, many types of behaviors, and many life history parameters (e.g. Seghers 1974; Farr 1975; Endler 1995; Magurran et al. 1995; Reznick 1996; Houde 1997; Reznick et al. 1997). Regarding only life history characters, guppies from high-predation populations are known to mature earlier and at a smaller size, produce more and smaller offspring per litter, reproduce more often, produce higher reproductive allotments, and exhibit longer reproductive lifespans than guppies from low-predation populations (Reznick and Endler 1982; Reznick et al. 1996; Reznick et al. 2006). Another livebearing fish, the Bahamas mosquitofish (Gambusia hubbsi), also exhibits striking 
phenotypic differences between predator regimes, including divergence in habitat use (Fig. 6A), body color (Fig. 6B), several life history parameters (Krumholz 1963; Sohn 1977; Downhower et al. 2000), male genital size (Langerhans et al. 2005), body shape (R.B. Langerhans unpublished data), and swimming performance (R.B. Langerhans unpublished data).
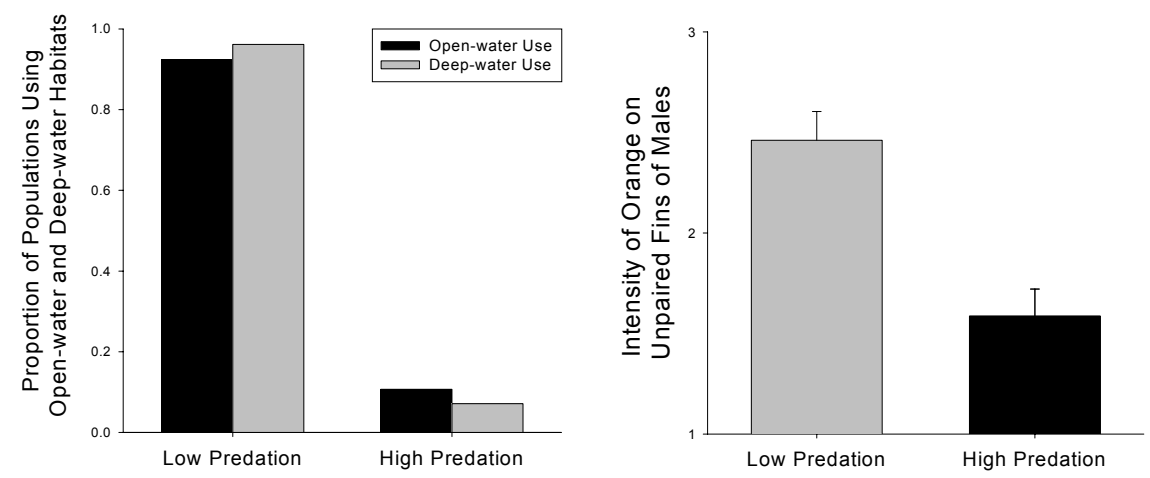

Fig. 6. Divergence in (A) habitat use and (B) body color among low- and highpredation environments in Bahamas mosquitofish (Gambusia hubbsi). Prey populations avoid dangerous habitat types (chi-square, $\mathrm{P}<0.0001$ ) and exhibit less conspicuous coloration (ANOVA, $\mathrm{P}<0.0001$ ) in high-predation populations ( $\mathrm{N}=55$ populations; 25 low-predation, 30 high-predation). Habitat use was easily assessed using underwater visual survey, and orange intensity was assessed by ranking individuals from 1 to 3 (1: low, 2: medium, 3: high). Data from RB Langerhans (unpublished data)

Other well-studied examples of phenotypic divergence between predator regimes for closely related populations or species includes threespine sticklebacks (Gasterosteus spp.) and Enallagma damselflies. For instance, sticklebacks exhibit greater levels of defensive armor and schooling behaviors under relatively high predation intensities (e.g. Vamosi 2002; Doucette et al. 2004; Reimchen and Nosil 2004; Vamosi and Schluter 2004), and Enallagma damselflies exhibit larger caudal lamellae and greater arginine kinase activity (enhancing rapid retreat) with predatory dragonflies (e.g. McPeek et al. 1996; McPeek 1997; McPeek 1999). In many cases, the presumed tradeoffs have been tested and the adaptive significance of the trait shifts have been identified. 


\subsubsection{Divergent selection within predator regimes: the search for enemy-free space}

Not only can divergent selection arise between alternative predator regimes, but predators can also drive divergent selection on prey traits within predator regimes (Fig. 4B). This is traditionally believed to stem from apparent competition - or competition for enemy-free space-which occurs when one species negatively impacts the density of another species, not through consumption of shared resources, but rather through a positive effect on the density of a shared predator. However, apparent competition - or even sympatry - is not required for predators to generate prey divergence within particular predator regimes (Abrams 2000). To date, this mode of predator-driven divergence has primarily received theoretical investigation (e.g. Fryer 1959; Holt 1977; Brown and Vincent 1992; Abrams 2000; Doebeli and Dieckmann 2000; Abrams and Chen 2002; Bowers et al. 2003), with empirical studies slow to venture into this field (e.g. Askew 1961; Clarke 1962; Owen 1963; Gilbert 1975; Ricklefs and O'Rourke 1975; Bond and Kamil 2002).

One way that trait divergence can be favored by predator-mediated selection within predator regimes is if predators are most efficient at detecting and consuming particular prey phenotypes, and deviations from these phenotypes in any direction would enhance prey fitness. For instance, if two prey populations differ in their average phenotype, with one slightly less and one slightly more than that most vulnerable to predation, then selection will drive the populations in opposite directions of phenotype space (Holt 1977). That is, there are multiple ways prey can reduce predation risk, but intermediate trait values exhibit low fitness. This type of divergence can further occur even when there is only one initial prey population, if predators are also allowed to evolve and prey additionally compete for limited resources (Brown and Vincent 1992). However, trait divergence is not the only possible outcome, as prey populations might also respond to predation in parallel manners (Abrams 2000). Although this scenario is typically discussed in a sympatric framework, trait divergence can actually occur via such a mechanism among either sympatric or allopatric prey populations. The particular adaptive peak a prey population might traverse can also be influenced by genetic drift or genetic constraints; in these cases, divergence can result from an interaction between predator-mediated natural selection and other evolutionary factors.

Schluter (2000) reviewed possible examples where divergent selection within predator regimes has resulted in prey divergence; examples include diversification of aspect diversity in moths (Ricklefs and O'Rourke 1975), 
leaf shape in passion flower vine species (Passiflora spp.) attacked by egglaying Heliconius butterflies (Gilbert 1975), and gall shapes in oak gall wasps attacked by parasitoids (Askew 1961). A potentially common scenario in nature that might produce divergent selection within predator regimes is when multiple types of background environments exist, and selection favors different means of crypticity in prey to avoid detection (e.g. Bond and Kamil 2002; Nosil 2004; Bond and Kamil 2006). Importantly, such divergent selection within predator regimes (i.e. selection caused by the same predatory agent) need not result from apparent competition, as predator density can remain constant and selection coefficients can also be unaffected by predator density.

\subsubsection{Divergent selection involving other selective agent(s): predation as a context shift}

Rather than acting as a direct selective force, predation can alter the environmental context for prey interactions, thus changing their selective regime (Fig. 4C; Buckling and Rainey 2002; Doucette et al. 2004; Eklöv and Svanbäck 2006; Steets et al. 2006). This arises when predators cause changes in prey traits or densities, or attributes of other community members, that result in changes in selection (magnitude and/or nature) experienced by prey. For example, predators often cause behavioral shifts in prey (Kotler and Brown 1988; Lima and Dill 1990; Peacor and Werner 2001; Lingle 2002; Fig. 6A) which might alter a prey's selective environment, possibly strengthening divergent selection already in place. Interestingly, predators need not even consume any individuals to drive phenotypic divergence in prey under this scenario. Such non-lethal effects of predators represent an important, growing field of study in ecology (see chapter 17), however, this topic is only now beginning to receive considerable attention by evolutionists. So far, it is unknown whether predators might weaken divergent selection among prey populations as often as they strengthen it.

One type of prey interaction that predation might often influence is resource competition. Predation appears to play an important role in the divergence of benthic and limnetic species pairs of threespine stickleback in British Columbia (e.g. Vamosi 2002; Vamosi and Schluter 2004). In a pond experiment, divergent selection among benthic and limnetic stickleback was strengthened under high predation pressure from aquatic insects and cutthroat trout (Oncorhynchus clarkii), even though the level of resource competition actually decreased (Rundle et al. 2003). In this case, it seems that predators increased resource partitioning among divergent 
prey phenotypes, possibly by inducing changes in habitat use or foraging behavior, and caused competition to decline at a greater rate with phenotypic distance compared to an environment lacking predators. Interestingly, benthic and limnetic pairs of stickleback have apparently evolved only in lakes with cutthroat trout and no other fish species present. Stickleback have not evolved such phenotypic divergence within any of 16 nearby candidate lakes, which have an average of approximately three other fish species, and all but one have more potential predators and competitors than cutthroat trout (Vamosi 2003).

\subsubsection{Predation as a driver of speciation: eating individuals, spitting out species}

Until now, we have only discussed predation's influence on phenotype divergence within lineages, however predation can also affect the splitting of lineages (i.e. speciation), the elimination of lineages (i.e. extinction), and overall diversification rates (speciation minus extinction). Both theoretical and empirical work strongly confirm that divergent selection can lead to speciation (i.e. reproductive isolation between populations) as a byproduct of ecological adaptation (e.g. Mayr 1942; Dobzhansky 1951; Rice and Hostert 1993; Funk 1998; Rundle et al. 2000; Schluter 2001; Coyne and Orr 2004; Nosil et al. 2005; Rundle and Nosil 2005; Funk et al. 2006). For example, mate choice might involve traits under divergent selection, or selection against hybrids might favor assortative mating. Further, predator-mediated selection against migrants from alternative predator regimes can result in reproductive isolation. Thus, any of the mechanisms described above could result in reproductive isolation between divergent prey populations. But, has predation actually been an important driver of speciation? Given the apparent ubiquity of predation's influence on phenotype divergence, it seems reasonable to expect that it might often contribute to the process of speciation. Unfortunately, investigation into predation's role in the formation of species has received little attention to date (see Fig. 1). However, recent work is beginning to shed some light onto this question (e.g. McPeek and Wellborn 1998; Stoks et al. 2005; Vamosi 2005).

There is now accumulating evidence suggesting predation is a significant driver of speciation in Heliconius butterflies (e.g. McMillan et al. 1997; Mallet et al. 1998; Jiggins et al. 2001; Naisbit et al. 2003; Jiggins et al. 2004). Further, predation is strongly implicated in divergence and reproductive isolation between color pattern morphs of Timema walkingstick insects (e.g. Sandoval 1994; Crespi and Sandoval 2000; Nosil et al. 
2002; Nosil et al. 2003; Nosil 2004; Nosil and Crespi 2006). In this case, predator-mediated divergent selection (by avian predators) across background environments (host plants) has apparently resulted in cryptic color pattern divergence and partial reproductive isolation between diverging prey populations. Ongoing work is also uncovering the importance of predation on reproductive isolation among populations of livebearing fish species inhabiting divergent predator regimes (RB Langerhans unpublished data).

Additionally, several general models of speciation might involve predation, although they may not typically focus on predation per se. For example, habitat selection (e.g. host-plant preference, oviposition site selection) can often be influenced by predator regime, and facilitate speciation by enhancing assortative mating. Further, many models of speciation involving frequency-dependent selection, or competition for resources, can be interpreted as consequences of predator-prey interactions (e.g. apparent competition).

\subsection{Conclusions and future directions}

Predation's general importance in the evolution of prey phenotypes is without question. In this chapter, I described a framework for understanding antipredator traits based on the manner in which traits influence prey fitness and the chronological sequence of predatory encounters. The framework illustrates the ubiquity of predation's influence on prey traits. However, many questions remain concerning the detailed nature of predation's role in generating the diversity of phenotypes and species we see today. This chapter highlights the need for further investigation into how reproductive strategies might reflect antipredator adaptations, and how predation might influence trait divergence and speciation. An important component of future research should involve a pluralistic approach to studies of phenotype evolution, where multiple selective agents and multiple phenotypes are examined simultaneously. While research into the significance of predation in producing evolutionary divergence of prey species experienced a slow start through most of the twentieth century, recent and ongoing research suggests the field is now very rapidly growing. Our understanding of the varied ways that predators might influence the evolution of prey phenotypes and reproductive isolation between prey populations should be greatly improved by the end of the current century. 


\subsection{Acknowledgements}

I thank A. Elewa for the opportunity to contribute to this book. The chapter was improved by comments from David Reznick and an anonymous reviewer. The author was supported by Washington University and an Environmental Protection Agency Science to Achieve Results fellowship.

\section{References}

Aarnio K, Bonsdorff E (1997) Passing the gut of juvenile flounder, Platichthys flesus: differential survival of zoobenthic prey species. Marine Biology 129 (1): $11-14$

Abrams PA (2000) Character shifts of prey species that share predators. American Naturalist 156 (4, Supplement): S45-S61

Abrams PA, Chen X (2002) The evolution of traits affecting resource acquisition and predator vulnerability: Character displacement under real and apparent competition. American Naturalist 160 (5): 692-704

Abrams PA, Rowe L (1996) The effects of predation on the age and size of maturity of prey. Evolution 50(3): 1052-1061

Acharya L, Fenton MB (1992) Echolocation behaviour of vespertillionid bats (Lasiurus cinereus and Lasiurus borealis) attacking airborne targets including arctiid moths. Canadian Journal of Zoology 70: 1292-1298

Addicott JF (1974) Predation and prey community structure: an experimental study of the effect of mosquito larvae on the protozoan communities of pitcher plants. Ecology 55: 475-492

Agrawal AA, Tuzun S, Bent E (1999) Induced plant defenses against pathogens and herbivores: biochemistry, ecology, and agriculture. American Phytopathological Society, St. Paul, MN

Almany GR, Webster MS (2004) Odd species out as predators reduce diversity of coral-reef fishes. Ecology 85 (11): 2933-2937

Andersson M (1994) Sexual selection. Princeton University Press, Princeton, NJ

Askew RR (1961) On the biology of the inhabitants of oak galls of Cynipidae (Hymenoptera) in Britain. Transactions of the Society for British Entomology 14: $237-268$

Bates HW (1862) Contributions to an insect fauna of the Amazon valley. Lepidoptera: Heliconidae. Transactions of the Linnean Society of London 23:495-566

Beddard FE (1892) Animal coloration: an account of the principal facts and theories related to the colours and markings of animals. Swan Sonnenschein \& Co., London

Bertram BC (1978) Predators and prey. In Krebs JR, Davies NB (eds) Behavioral ecology: an evolutionary approach. Blackwell, Oxford 64-96 
Blackledge TA, Coddington JA, Gillespie RG (2003) Are three-dimensional spider webs defensive adaptations? Ecology Letters 6 (1): 13-18

Blake RW (1983) Fish locomotion. Cambridge University Press, Cambridge

Blake RW (2004) Fish functional design and swimming performance. Journal of Fish Biology 65 (5): 1193-1222

Bond AB, Kamil AC (2002) Visual predators select for crypticity and polymorphism in virtual prey. Nature 415 (6872): 609-613

Bond AB, Kamil AC (2006) Spatial heterogeneity, predator cognition, and the evolution of color polymorphism in virtual prey. Proceedings of the National Academy of Sciences of the United States of America 103 (9): 3214-3219

Bowers DM (1993) Aposematic caterpillars: life-styles of the warningly colored and unpalatable. In Stamp NE, Casey TM (eds) Caterpillars: ecological and evolutionary constraints on foraging. Chapman \& Hall, New York 331-371

Bowers RG, White A, Boots M, Geritz SAH, Kisdi E (2003) Evolutionary branching/speciation: contrasting results from systems with explicit or emergent carrying capacities. Evolutionary Ecology Research 5 (6): 883-891

Boycott BB (1958) The cuttlefish - Sepia. New Biology 25: 98-118

Bradshaw AD (1965) Evolutionary significance of phenotypic plasticity in plants. Advances in Genetics 13: 115-155

Brakefield PM, Shreeve TM, Thomas JM (1992) Avoidance, concealment, and defence. In Dennis RLH (ed) The ecology of butterflies in Britain. Oxford University Press, Oxford 93-119

Brinkhof MWG, Cave AJ, Hage FJ, Verhulst S (1993) Timing of reproduction and fledging success in the coot Fulica atra: evidence for a causal relationship. Journal of Animal Ecology 62 (3): 577-587

Brodie ED, Jr. (1968) Investigations on the skin toxin of the adult roughskinned newt, Taricha granulosa. Copeia: 307-313

Brooke MD (1998) Ecological factors influencing the occurrence of 'flash marks' in wading birds. Functional Ecology 12 (3): 339-346

Brown JS (1999) Vigilance, patch use and habitat selection: foraging under predation risk. Evolutionary Ecology Research 1 (1): 49-71

Brown JS, Vincent TL (1992) Organization of predator-prey communities as an evolutionary game. Evolution 46 (5): 1269-1283

Buckling A, Rainey PB (2002) The role of parasites in sympatric and allopatric host diversification. Nature 420 (6915): 496-499

Cain AJ, Sheppard PM (1954) Natural selection in Cepaea. Genetics 39: 89-116

Caldwell JP (1982) Disruptive selection: a tail color polymorphism in Acris tadpoles in response to differential predation. Canadian Journal of Zoology 60: $2818-2827$

Caro TM (2005) Antipredator defenses in birds and mammals. University of Chicago Press, Chicago

Caumul R, Polly PD (2005) Phylogenetic and environmental components of morphological variation: skull, mandible, and molar shape in marmots (Marmota, Rodentia). Evolution 59 (11): 2460-2472

Chapman LJ, Chapman CA, Chandler M (1996a) Wetland ecotones as refugia for endangered fishes. Biological Conservation 78 (3): 263-270 
Chapman LJ, Chapman CA, Nordlie FG, Rosenberger AE (2002) Physiological refugia: swamps, hypoxia tolerance and maintenance of fish diversity in the Lake Victoria region. Comparative Biochemistry and Physiology A 133 (3): 421-437

Chapman LJ, Chapman CA, Ogutu-Ohwayo R, Chandler M, Kaufman L, Keiter AE (1996b) Refugia for endangered fishes from an introduced predator in Lake Nabugabo, Uganda. Conservation Biology 10 (2): 554-561

Chivers DP, Kiesecker JM, Marco A, DeVito J, Anderson MT, Blaustein AR (2001) Predator-induced life history changes in amphibians: egg predation induces hatching. Oikos 92 (1): 135-142

Chivers DP, Smith RJF (1998) Chemical alarm signalling in aquatic predator-prey systems: a review and prospectus. Ecoscience 5 (3): 338-352

Clarke B (1962) Balanced polymorphism and the diversity of sympatric species. Systematics Association Publications, London

Conover DO, Munch SB (2002) Sustaining fisheries yields over evolutionary time scales. Science 297 (5578): 94-96

Cott HB (1940) Adaptive coloration in animals. Methuen, London

Coyne JA, Orr HA (2004) Speciation. Sinauer Associates, Sunderland, MA

Crespi BJ, Sandoval CP (2000) Phylogenetic evidence for the evolution of ecological specialization in Timema walking-sticks. Journal of Evolutionary Biology 13 (2): 249-262

Crowl TA, Covich AP (1990) Predator-induced life-history shifts in a freshwater snail. Science 247 (4945): 949-950

Darling FF (1938) Bird flocks and breeding cycles. Cambridge University Press, Cambridge

Darwin C (1871) The descent of man and selection in relation to sex. John Murray, London

Dayton GH, Saenz D, Baum KA, Langerhans RB, DeWitt TJ (2005) Body shape, burst speed and escape behavior of larval anurans. Oikos 111 (3): 582-591

de Ruiter PC, Wolters V, Moore JC (2005) Dynamic food webs: multispecies assemblages, ecosystem development and environmental change. Academic Press, Burlington, MA

DeVito J, Chivers DP, Kiesecker JM, Marco A, Wildy EL, Blaustein AR (1998) The effects of snake predation on metamorphosis of western toads, Bufo boreas (Amphibia, Bufonidae). Ethology 104 (3): 185-193

DeWitt TJ (1996) Functional tradeoffs and phenotypic plasticity in the freshwater snail Physa. Binghamton University, Binghamton, New York

DeWitt TJ, Langerhans RB (2003) Multiple prey traits, multiple predators: keys to understanding complex community dynamics. Journal of Sea Research 49 (2): 143-155

DeWitt TJ, Langerhans RB (2004) Integrated solutions to environmental heterogeneity: theory of multimoment reaction norms. In DeWitt TJ, Scheiner SM (eds) Phenotypic plasticity. Functional and conceptual approaches. Oxford University Press, New York 98-111 
DeWitt TJ, Robinson BW, Wilson DS (2000) Functional diversity among predators of a freshwater snail imposes an adaptive trade-off for shell morphology. Evolutionary Ecology Research 2 (2): 129-148

DeWitt TJ, Scheiner SM (2004) Phenotypic plasticity. Functional and conceptual approaches. Oxford University Press, New York

DeWitt TJ, Sih A, Hucko JA (1999) Trait compensation and cospecialization in a freshwater snail: size, shape and antipredator behavior. Animal Behaviour 58: 397-407

Dice LR (1947) Effectiveness of selection by owls of deer mice (Peromyscus maniculatus) which contrast in colour with their background. Contributions from the Laboratory of Vertebrate Biology, University of Michigan 34: 1-20

Dobzhansky T (1951) Genetics and the origin of species. Columbia University Press

Dodson S (1989) Predator-induced reaction norms. Bioscience 39 (7): 447-452

Doebeli M, Dieckmann U (2000) Evolutionary branching and sympatric speciation caused by different types of ecological interactions. American Naturalist 156(4, Supplement): S77-S101

Dohm MR, Hayes JP, Garland T (1996) Quantitative genetics of sprint running speed and swimming endurance in laboratory house mice (Mus domesticus). Evolution 50 (4): 1688-1701

Domenici P (2003) Habitat, body design and the swimming performance of fish. In Bels VL, Gasc J-P Casinos A (eds) Vertebrate biomechanics and evolution. BIOS Scientific Publishers Ltd, Oxford 137-160

Domenici P, Blake RW (1997) The kinematics and performance of fish fast-start swimming. Journal of Experimental Biology 200 (8): 1165-1178

Doucette LI, Skulason S, Snorrason SS (2004) Risk of predation as a promoting factor of species divergence in threespine sticklebacks (Gasterosteus aculeatus L.). Biological Journal of the Linnean Society 82 (2): 189-203

Downhower JF, Brown LP, Matsui ML (2000) Life history variation in female Gambusia hubbsi. Environmental Biology of Fishes 59 (4): 415-428

Driver PM, Humphries DA (1988) Protean behavior: the biology of unpredictability. Oxford University Press, Oxford

Edmunds M (1974) Defence in animals: a survey of anti-predator defences. Longman, New York

Ehrlich PR, Raven PH (1964) Butterflies and plants: a study in coevolution. Evolution 18: 586-608

Eisner T, Meinwald J (1966) Defensive secretions of arthropods. Science 153: $1341-1350$

Eklöv P, Svanbäck R (2006) Predation risk influences adaptive morphological variation in fish populations. American Naturalist 167 (3): 440-452

Elton CS (1927) Animal ecology. Sidgwick and Jackson, London

Endler JA (1978) A predator's view of animal color patterns. Evolutionary Biology 11: 319-364

Endler JA (1991) Interactions between predators and prey. In Krebs JR, Davies NB (eds) Behavioural ecology: an evolutionary approach. Blackwell Scientific Publications, Oxford 169-196 
Endler JA (1995) Multiple-trait coevolution and environmental gradients in guppies. Trends in Ecology \& Evolution 10 (1): 22-29

Ewer RF (1966) Juvenile behaviour of the African ground squirrel, Xerus erythropus (E. Geoff.). Zeitschrift für Tierpsychologie 23: 190-216

Farr JA (1975) Role of predation in evolution of social behavior of natural populations of the guppy, Poecilia reticulata (Pisces: Poeciliidae). Evolution 29 (1): $151-158$

Fryer G (1959) Some aspects of evolution in Lake Nyasa. Evolution 13: 440-451

Funk DJ (1998) Isolating a role for natural selection in speciation: host adaptation and sexual isolation in Neochlamisus bebbianae leaf beetles. Evolution 52 (6): 1744-1759

Funk DJ, Nosil P, Etges WJ (2006) Ecological divergence exhibits consistently positive associations with reproductive isolation across disparate taxa. Proceedings of the National Academy of Sciences of the United States of America 103 (9): 3209-3213

Galton F (1871) Gregariousness in cattle and men. MacMillan's Magazine 23: 353-357

Gauthier-Clerc M, Tamisier A, Cezilly F (1998) Sleep-vigilance trade-off in green-winged teals (Anas crecca crecca). Canadian Journal of Zoology 76 (12): 2214-2218

Ghalambor CK, Reznick DN, Walker JA (2004) Constraints on adaptive evolution: the functional trade-off between reproduction and fast-start swimming performance in the Trinidadian guppy (Poecilia reticulata). American Naturalist 164 (1): 38-50

Gilbert LE (1975) Ecological consequences of a coevolved mutualism between butterflies and plants. In Gilbert LE, Raven PH (eds) Coevolution of animals and plants. University of Texas Press, Austin 210-240

Gochfeld M (1982) Reproductive synchrony and predator satiation: an analogy between the Darling effect in birds and mast fruiting in plants. Auk 99: 586587

Gotthard K, Nylin S (1995) Adaptive plasticity and plasticity as an adaptation: a selective review of plasticity in animal morphology and life-history. Oikos 74 (1): 3-17

Gould SJ, Lewontin RC (1979) The spandrels of San Marco and the panglossian paradigm: a critique of the adaptationist programme. Proceedings of the Royal Society of London Series B-Biological Sciences 205: 581-598

Greene HW (1988) Antipredator mechanisms in reptiles. In Gans C, Huey RB (eds) Biology of the reptilia. Alan R. Liss, Inc., New York 1-152

Hairston NG (1987) Diapause as a predator avoidance adaptation. In Kerfoot WC, Sih A (eds) Predation: direct and indirect impacts on aquatic communities. University Press of New England, Hanover, NH 281-290

Hale ME, Long JH, McHenry MJ, Westneat MW (2002) Evolution of behavior and neural control of the fast-start escape response. Evolution 56 (5): 9931007

Hamilton WD (1971) Geometry for the selfish herd. Journal of Theoretical Biology 31 (2): 295-311 
Hanifin CT, Yotsu-Yamashita M, Yasumoto T, Brodie ED (1999) Toxicity of dangerous prey: variation of tetrodotoxin levels within and among populations of the newt Taricha granulosa. Journal of Chemical Ecology 25 (9): 2161-2175

Härlin C, Härlin M (2003) Towards a historization of aposematism. Evolutionary Ecology 17 (2): 197-212

Harvey PH, Greenwood PJ (1978) Anti-predator defence strategies: some evolutionary problems. In Krebs JR, Davies NB (eds) Behavioural ecology: an evolutionary approach. Blackwell Scientific Publications, Oxford

Havel JE (1987) Predator-induced defenses: a review. In Kerfoot WC, Sih A (eds) Predation: direct and indirect impacts on aquatic communities. University Press of New England, Hanover, N.H. 263-278

Helfman G, Collette B, Facey D (1997) The Diversity of Fishes. Blackwell Science, Malden, MA

Hoff KV, Wassersug RJ (2000) Tadpole locomotion: axial movement and tail functions in a largely vertebraeless vertebrate. American Zoologist 40 (1): 6276

Holling CS (1959) The components of predation as revealed by a study of small mammal predation of the European pine sawfly. Canadian Entomologist 91: 293-320

Holmes W (1940) The colour changes and colour paterns of Sepia officinalis L. Proceedings of the Zoological Society of London 110: 17-35

Holt RD (1977) Predation, apparent competition, and the structure of prey communities. Theoretical Population Biology 12: 197-229

Holt RD, Lawton JH (1994) The ecological consequences of shared natural enemies. Annual Review of Ecology and Systematics 25: 495-520

Honma A, Oku S, Nishida T (2006) Adaptive significance of death feigning posture as a specialized inducible defence against gape-limited predators. Proceedings of the Royal Society of London Series B-Biological Sciences 273 (1594): 1631-1636

Houde AE (1997) Sex, color, and mate choice in guppies. Princeton University Press, Princeton, N.J.

Hoverman JT, Auld JR, Relyea RA (2005) Putting prey back together again: integrating predator-induced behavior, morphology, and life history. Oecologia 144 (3): 481-491

Hoy R, Nolen T, Brodfuehrer P (1989) The neuroethology of acoustic startle and escape in flying insects. Journal of Experimental Biology 146: 287-306

Hubbs C (1996) Geographic variation in life history traits of Gambusia species. Proceedings of the Desert Fishes Council 27: 1-21

Huffaker CB (1958) Experimental studies on predation: dispersion factors and predator-prey oscillations. Hilgardia 27: 343-383

Humphries DA, Driver PM (1967) Erratic display as a device against predators. Science 156: 1767-1768

Humphries DA, Driver PM (1971) Protean defence by prey animals. Oecologia 5: 285-302 
Ims RA (1990) On the adaptive value of reproductive synchrony as a predatorswamping strategy. American Naturalist 136 (4): 485-498

Isley FB (1938) Survival value of acridian protective coloration. Ecology 19 (3): 370-389

Istock CA (1967) The evolution of complex life cycle phenomena: and ecological perspective. Evolution 21: 592-605

Jackson DA, Peres-Neto PR, Olden JD (2001) What controls who is where in freshwater fish communities - the roles of biotic, abiotic, and spatial factors. Canadian Journal of Fisheries and Aquatic Sciences 58 (1): 157-170

Janzen DH (1981) Evolutionary physiology of personal defense. In Townsend CR, Calow P (eds) Physiological ecology: an evolutionary approach to resource use. Blackwell, Oxford 145-164

Janzen FJ, Tucker JK, Paukstis GL (2000) Experimental analysis of an early lifehistory stage: avian predation selects for larger body size of hatchling turtles. Journal of Evolutionary Biology 13 (6): 947-954

Jeffries MJ, Lawton JH (1984) Enemy free space and the structure of ecological communities. Biological Journal of the Linnean Society 23: 269-286

Jiggins CD, Estrada C, Rodrigues A (2004) Mimicry and the evolution of premating isolation in Heliconius melpomene Linnaeus. Journal of Evolutionary Biology 17 (3): 680-691

Jiggins CD, Naisbit RE, Coe RL, Mallet J (2001) Reproductive isolation caused by colour pattern mimicry. Nature 411 (6835): 302-305

Karban R, Baldwin IT (1997) Induced responses to herbivory. University of Chicago Press, Chicago

Kenward RE (1978) Hawks and doves: factors affecting success and selection in goshawk attacks on wood pigeons. Journal of Animal Ecology 47: 449-460

Kerfoot WC, Sih A (1987) Predation: direct and indirect impacts on aquatic communities. University Press of New England, Hanover, NH.

Kettlewell HBD (1956) Further selection experiments on industrial melanism in the Lepidoptera. Heredity 10: 287-301

Kiltie RA (1988) Countershading: universally deceptive or deceptively universal. Trends in Ecology \& Evolution 3 (1): 21-23

Koehl MAR (1996) When does morphology matter? Annual Review of Ecology and Systematics 27: 501-542

Komárek S (1998) Mimicry, aposematism and related phenomena in animals and plants: bibliography 1800-1990. Vesmir, Prague

Kotler BP, Brown JS (1988) Environmental heterogeneity and the coexistence of desert rodents. Annual Review of Ecology and Systematics 19: 281-307

Kozlowski J, Uchmanski J (1987) Optimal individual growth and reproduction in perennial species with indeterminate growth. Evolutionary Ecology 1: 214230

Krumholz L (1963) Relationships between fertility, sex ratio, and exposure to predation in populations of the mosquitofish, Gambusia manni at Bimini, Bahamas. Internationale Revue der gesamten Hydrobiologie 48: 201-256

Lack D (1954) The natural regulation of animal numbers. Clarendon, Oxford 
Lande R, Arnold SJ (1983) The measurement of selection on correlated characters. Evolution 37 (6): 1210-1226

Langerhans RB, DeWitt TJ (2004) Shared and unique features of evolutionary diversification. American Naturalist 164 (3): 335-349

Langerhans RB, Layman CA, DeWitt TJ (2005) Male genital size reflects a tradeoff between attracting mates and avoiding predators in two live-bearing fish species. Proceedings of the National Academy of Sciences of the United States of America 102 (21): 7618-7623

Langerhans RB, Layman CA, Shokrollahi AM, DeWitt TJ (2004) Predator-driven phenotypic diversification in Gambusia affinis. Evolution 58 (10): 2305-2318

Levins R (1968) Evolution in changing environments. Princeton University Press, NJ.

Lev-Yadun S, Dafni A, Inbar M, Izhaki I, Ne'eman G (2002) Colour patterns in vegetative parts of plants deserve more research attention. Trends in Plant Science 7: 59-60

Lima SL, Dill LM (1990) Behavioral decisions made under the risk of predation: a review and prospectus. Canadian Journal of Zoology 68 (4): 619-640

Lindeman RL (1942) The trophic-dynamic aspect of ecology. Ecology 23: 377418

Lingle S (2002) Coyote predation and habitat segregation of white-tailed deer and mule deer. Ecology 83 (7): 2037-2048

Lloyd DG (1987) Selection of offspring size at independence and other sizeversus-number strategies. American Naturalist 129 (6): 800-817

Lloyd M, Dybas HS (1966) The periodical cicada problem. I. Population ecology. Evolution 20 (2): 133-149

MacArthur RH (1962) Some generalized theorems of natural selection. Proceedings of the National Academy of Sciences of the United States of America 48: 1893-1897

MacArthur RH, Wilson EO (1967) The theory of island biogeography. Princeton University Press, Princeton, New Jersey, USA

Magurran AE, Seghers, B. H., Shaw PW, Carvalho GR (1995) The behavioral diversity and evolution of guppy, Poecilia reticulata, populations in Trinidad. Advances in the study of behavior 24: 155-202

Mallet J, Joron M (1999) Evolution of diversity in warning color and mimicry: polymorphisms, shifting balance, and speciation. Annual Review of Ecology and Systematics 30: 201-233

Mallet J, McMillan WO, Jiggins CD (1998) Mimicry and warning color at the boundary between races and species. In Howard DJ, Berlocher SH (eds) Endless forms: species and speciation. Oxford University Press, New York 390-403

Mangel M, Clark CW (1988) Dynamic modeling in behavioral ecology. Princeton University Press, Princeton

Mayr E (1942) Systematics and the origin of species. Columbia University Press, New York 
McCollum SA, Van Buskirk J (1996) Costs and benefits of a predator-induced polyphenism in the gray treefrog Hyla chrysoscelis. Evolution 50 (2): 583 593

McMillan WO, Jiggins CD, Mallet J (1997) What initiates speciation in passionvine butterflies? Proceedings of the National Academy of Sciences of the United States of America 94 (16): 8628-8633

McPeek MA (1995) Morphological evolution mediated by behavior in the damselflies of two communities. Evolution 49 (4): 749-769

McPeek MA (1997) Measuring phenotypic selection on an adaptation: lamellae of damselflies experiencing dragonfly predation. Evolution 51 (2): 459-466

McPeek MA (1999) Biochemical evolution associated with antipredator adaptation in damselflies. Evolution 53 (6): 1835-1845

McPeek MA, Schrot AK, Brown JM (1996) Adaptation to predators in a new community: swimming performance and predator avoidance in damselflies. Ecology 77 (2): 617-629

McPeek MA, Wellborn GA (1998) Genetic variation and reproductive isolation among phenotypically divergent amphipod populations. Limnology and Oceanography 43 (6): 1162-1169

Mcphail JD (1969) Predation and the evolution of a stickleback (Gasterosteus). Journal of Fisheries Research Board of Canada 26: 3183-3208

Miller RC (1922) The significance of the gregarious habit. Ecology 3 (2): 122-126

Moran AL, Emlet RB (2001) Offspring size and performance in variable environments: field studies on a marine snail. Ecology 82 (6): 1597-1612

Morgan MJ, Godin J-GJ (1985) Antipredator benefits of schooling behaviour in a cyprinodontid fish, the banded killifish (Fundulus diaphanus). Zeitschrift für Tierpsychologie 70: 236-246

Mostler G (1935) Beobachtungen zur frage der wespenmimikry. Zeitschrift für Morphologie und Ökologie der Tiere 29: 381-454

Müller F (1879) Ituna and Thyridia; a remarkable case of mimicry in butterflies. Transactions of the Entomological Society of London: xx-xxix

Myers JH, Bazely D (1991) Thorns, spines, prickles, and hairs: are they stimulated by herbivory and do they deter herbivores? In Tallamy DW, Raupp MJ (eds) Phytochemical induction by herbivores. John Wiley and Sons, New York 325-345

Naisbit RE, Jiggins CD, Mallet J (2003) Mimicry: developmental genes that contribute to speciation. Evolution \& Development 5 (3): 269-280

Newman RA (1988) Adaptive plasticity in development of Scaphiopus couchii tadpoles in desert ponds. Evolution 42 (4): 774-783

Norris KS, Lowe CH (1964) An analysis of background color-matching in amphibians and reptiles. Ecology 45 (3): 565-580

Nosil P (2004) Reproductive isolation caused by visual predation on migrants between divergent environments. Proceedings of the Royal Society of London Series B-Biological Sciences 271 (1547): 1521-1528

Nosil P, Crespi BJ (2006a) Ecological divergence promotes the evolution of cryptic reproductive isolation. Proceedings of the Royal Society of London Series B-Biological Sciences 273: 991-997 
Nosil P, Crespi BJ (2006b) Experimental evidence that predation promotes divergence in adaptive radiation. Proceedings of the National Academy of Sciences of the United States of America 103 (24): 9090-9095

Nosil P, Crespi BJ, Sandoval CP (2002) Host-plant adaptation drives the parallel evolution of reproductive isolation. Nature 417 (6887): 440-443

Nosil P, Crespi BJ, Sandoval CP (2003) Reproductive isolation driven by the combined effects of ecological adaptation and reinforcement. Proceedings of the Royal Society of London Series B-Biological Sciences 270 (1527): 19111918

Nosil P, Vines TH, Funk DJ (2005) Perspective: reproductive isolation caused by natural selection against immigrants from divergent habitats. Evolution 59 (4): 705-719

Owen DF (1963) Polymorphism and population density in the African land snail Limicolaria martensiana. Science 140: 666-667

Paine RT (1966) Food web complexity and species diversity. American Naturalist 100 (910): 65-76

Palleroni A, Miller CT, Hauser M, Marler P (2005) Predation Prey plumage adaptation against falcon attack. 434 (7036): 973-974

Peacor SD, Werner EE (2001) The contribution of trait-mediated indirect effects to the net effects of a predator. Proceedings of the National Academy of Sciences of the United States of America 98 (7): 3904-3908

Pigliucci M (2001) Phenotypic plasticity. Beyond nature and nature. Johns Hopkins University Press, Baltimore, MD

Pigliucci M, Murren CJ (2003) Genetic assimilation and a possible evolutionary paradox: can macroevolution sometimes be so fast as to pass us by? Evolution 57 (7): 1455-1464

Pigliucci M, Preston K (2004) The evolutionary biology of complex phenotypes. Oxford University Press, New York

Pimm SL (1982) Food Webs. Chapman and Hall, London, England

Polis GA, Winemiller KO (1996) Food webs : integration of patterns \& dynamics. Chapman \& Hall, New York

Poulton EB (1890) The colours of animals: their meaning and use especially considered in the case of insects. Kegan Paul, Trench, Trübner and Co. Ltd., London

Poulton EB (1902) The meaning of the white undersides of animals. Nature 65: 596

Price TD, Qvarnstrom A, Irwin DE (2003) The role of phenotypic plasticity in driving genetic evolution. Proceedings of the Royal Society of London Series B-Biological Sciences 270 (1523): 1433-1440

Pulliam HR (1973) On the advantages of flocking. Journal of Theoretical Biology 38 (2): 419-422

Pulliam HR, Caraco T (1984) Living in groups: is there an optimal group size? In Krebs JR, Davies NB (eds) Behavioural ecology: an evolutionary approach. Sinauer, Sunderland, MA 122-147

Reidy S, Kerr S, Nelson J (2000) Aerobic and anaerobic swimming performance of individual Atlantic cod. Journal of Experimental Biology 203 (2): 347-357 
Reimchen TE (1994) Predators and morphological evolution in threespine stickleback. In Bell MA, Foster SA (eds) The evolutionary biology of the threespine stickleback. Oxford University Press, Oxford 240-276

Reimchen TE, Nosil P (2002) Temporal variation in divergent selection on spine number in threespine stickleback. Evolution 56 (12): 2472-2483

Reimchen TE, Nosil P (2004) Variable predation regimes predict the evolution of sexual dimorphism in a population of threespine stickleback. Evolution 58 (6): $1274-1281$

Relyea RA (2002) Local population differences in phenotypic plasticity: predatorinduced changes in wood frog tadpoles. Ecological Monographs 72(1): 77-93

Reznick DN (1996) Life history evolution in guppies: a model system for the empirical study of adaptation. Netherlands Journal of Zoology 46 (3-4): 172190

Reznick DN, Bryant M, Holmes D (2006a) The evolution of senescence and postreproductive lifespan in guppies (Poecilia reticulata). PLoS Biology 4 (1): 136-143

Reznick DN, Bryga H, Endler JA (1990) Experimentally induced life-history evolution in a natural population. Nature 346 (6282): 357-359

Reznick DN, Butler MJ, Rodd FH, Ross P (1996) Life-history evolution in guppies (Poecilia reticulata). 6. Differential mortality as a mechanism for natural selection. Evolution 50 (4): 1651-1660

Reznick DN, Endler JA (1982) The impact of predation on life history evolution in Trinidadian guppies (Poecilia reticulata). Evolution 36: 160-177

Reznick DN, Schultz E, Morey S, Roff D (2006b) On the virtue of being the first born: the influence of date of birth on fitness in the mosquitofish, Gambusia affinis. Oikos 113 (1): 135-147

Reznick DN, Shaw FH, Rodd FH, Shaw RG (1997) Evaluation of the rate of evolution in natural populations of guppies (Poecilia reticulata). Science 275 (5308): 1934-1937

Rice WR, Hostert EE (1993) Laboratory experiments on speciation: what have we learned in 40 years? Evolution 47 (6): 1637-1653

Ricklefs RE, O'Rourke K (1975) Aspect diversity in moths: a temperate-tropical comparison. Evolution 29: 313-324

Rigby MC, Jokela J (2000) Predator avoidance and immune defense: costs and trade-offs in snails. Proceedings of the Royal Society of London Series BBiological Sciences 267: 171-176

Riley AM, Loxdale HD (1988) Possible adaptive significance of "tail" structure in "false head" lycaenid butterflies. Entomologists Record and Journal of Variation 84: 349-365

Robinson BW, Parsons KJ (2002) Changing times, spaces, and faces: tests and implications of adaptive morphological plasticity in the fishes of northern postglacial lakes. Canadian Journal of Fisheries and Aquatic Sciences 59 (11): 1819-1833

Robinson MH (1969) Defenses against visually hunting predators. In Dobzhansky T, Hecht MK, Steere WC (eds) Evolutionary Biology. Meredith Corporation, New York 
Roeder KD (1962) The behaviour of free flying moths in the presence of artificial ultrasonic pulses. Animal Behaviour 10: 300-304

Roeder KD (1965) Moths and ultrasound. Scientific American 212 (4): 94-102

Roff DA (1992) The evolution of life histories: theory and analysis. Chapman \& Hall, New York

Roff DA (2002) Life history evolution. Sinauer Associates Inc., Sunderland, MA

Rundle HD, Nagel L, Boughman JW, Schluter D (2000) Natural selection and parallel speciation in sympatric sticklebacks. Science 287 (5451): 306-308

Rundle HD, Nosil P (2005) Ecological speciation. Ecology Letters 8 (3): 336-352

Rundle HD, Vamosi SM, Schluter D (2003) Experimental test of predation's effect on divergent selection during character displacement in sticklebacks. Proceedings of the National Academy of Sciences of the United States of America 100 (25): 14943-14948

Ruxton GD, Sherratt TN, Speed MP (2004) Avoiding attack: the evolutionary ecology of crypsis, warning signals and mimicry. Oxford University Press, Oxford

Rydell J, Jones G, Waters D (1995) Echolocating bats and hearing moths: who are the winners. Oikos 73 (3): 419-424

Saenz D, Johnson JB, Adams CK, Dayton GH (2003) Accelerated hatching of southern leopard frog (Rana sphenocephala) eggs in response to the presence of a crayfish (Procambarus nigrocinctus) predator. Copeia (3): 646-649

Sandoval CP (1994) Differential visual predation on morphs of Timema cristinae (Phasmatodeae: Timemidae) and its consequences for host range. Biological Journal of the Linnean Society 52 (4): 341-356

Schaack S, Chapman LJ (2003) Interdemic variation in the African cyprinid Barbus neumayeri: correlations among hypoxia, morphology, and feeding performance. Canadian Journal of Zoology 81 (3): 430-440

Scheiner SM (1993) Genetics and evolution of phenotypic plasticity. Annual Review of Ecology and Systematics 24 (35-68): 35-68

Schlichting CD (2004) The role of phenotypic plasticity in diversification. In DeWitt TJ, Scheiner SM (eds) Phenotypic plasticity. Functional and conceptual approaches. Oxford University Press, New York 191-200

Schlichting CD, Pigliucci M (1998) Phenotypic evolution: a reaction norm perspective. Sinauer, Sunderland, MA

Schluter D (2000) The ecology of adaptive radiation. Oxford University Press, Oxford

Schluter D (2001) Ecology and the origin of species. Trends in Ecology and Evolution 16 (7): 372-380

Seghers BH (1974) Schooling behavior in the guppy (Poecilia reticulata): an evolutionary response to predation. Evolution 28: 486-489

Shurin JB, Allen EG (2001) Effects of competition, predation, and dispersal on species richness at local and regional scales. American Naturalist 158 (6): 624-637

Sih A (1987) Predators and prey lifestyles: an evolutionary and ecological overview. In Kerfoot WC, Sih A (eds) Predation: Direct and Indirect Impacts 
on Aquatic Communities. University Press of New England, Hanover, NH 203-224

Sohn JJ (1977) Consequences of predation and competition upon demography of Gambusia manni (Pisces: Poeciliidae). Copeia: 224-227

Stanley SM (1979) Macroevolution, pattern and process. W.H. Freeman, San Francisco

Stearns SC, Crandall RE (1981) Quantitative predictions of delayed maturity. Evolution 35 (3): 455-463

Steets JA, Salla R, Ashman TL (2006) Herbivory and competition interact to affect reproductive traits and mating system expression in Impatiens capensis. American Naturalist 167 (4): 591-600

Stein RA (1979) Behavioral response of prey to fish predators. In Stroud RH, Clepper H (eds) Predator-prey systems in fisheries management. Sport Fishing Institute, Washington, D.C.

Stemberger RS, Gilbert JJ (1987) Defenses of planktonic rotifers against predators. In Kerfoot WC, Sih A (eds) Predation: direct and indirect impacts on aquatic communities. University Press of New England, Hanover, NH 227-239

Stoks R, Nystrom JL, May ML, McPeek MA (2005) Parallel evolution in ecological and reproductive traits to produce cryptic damselfly species across the holarctic. Evolution 59 (9): 1976-1988

Sumner FB (1934) Does protective coloration protect? Results of some experiments with fishes and birds. Proceedings of the National Academy of Sciences of the United States of America 20 (10): 559-564

Thayer AH (1896) The law which underlies protective coloration. Auk 13 (2): 124-129

Thomson AL (1950) Factors determining the breeding seasons of birds: an introductory review. Ibis 92: 173-184

Tollrian R, Harvell CD (1999) The ecology and evolution of inducible defenses. Princeton University Press, Princeton

Treat AE (1955) The response to sound in certain Lepidoptera. Annals of the Entomological Society of America 48: 272-284

Trehorne JE, Foster WA (1980) The effects of group size on predator avoidance in a marine insect. Animal Behaviour 28: 1119-1122

Vamosi SM (2002) Predation sharpens the adaptive peaks: survival trade-offs in sympatric sticklebacks. Annales Zoologici Fennici 39 (3): 237-248

Vamosi SM (2003) The presence of other fish species affects speciation in threespine sticklebacks. Evolutionary Ecology Research 5 (5): 717-730

Vamosi SM (2005) On the role of enemies in divergence and diversification of prey: a review and synthesis. Canadian Journal of Zoology 83 (7): 894-910

Vamosi SM, Schluter D (2002) Impacts of trout predation on fitness of sympatric sticklebacks and their hybrids. Proceedings of the Royal Society of London Series B-Biological Sciences 269 (1494): 923-930

Vamosi SM, Schluter D (2004) Character shifts in the defensive armor of sympatric sticklebacks. Evolution 58 (2): 376-385 
Van Buskirk J, Anderwald P, Lupold S, Reinhardt L, Schuler H (2003) The lure effect, tadpole tail shape, and the target of dragonfly strikes. Journal of Herpetology 37 (2): 420-424

Vanhooydonck B, Van Damme R, Aerts P (2001) Speed and stamina trade-off in lacertid lizards. Evolution 55 (5): 1040-1048

Van Noordwijk AJ, Mccleery RH, Perrins CM (1995) Selection for the timing of great tit breeding in relation to caterpillar growth and temperature. Journal of Animal Ecology 64 (4): 451-458

Vermeij GJ (1982) Unsuccessful predation and evolution. American Naturalist 120 (6): 701-720

Vermeij GJ (1987) Evolution and Escalation. Princeton University Press, Princeton, NJ

Videler JJ (1993) Fish swimming. Chapman \& Hall, London

Vine I (1971) Risk of visual detection and pursuit by a predator and the selective advantage of flocking behaviour. Journal of Theoretical Biology 30 (2): 405422

Vinyard G (1979) An ostracod (Cypriodopsis vidua) can reduce predation from fish by resisting digestion. American Midland Naturalist 102 (1): 188-190

Viscido SV, Miller M, Wethey DS (2001) The response of a selfish herd to an attack from outside the group perimeter. Journal of Theoretical Biology 208 (3): $315-328$

Vogel S (1994) Life in moving fluids. Princeton University Press, Princeton

Vonesh JR (2005) Egg predation and predator-induced hatching plasticity in the African reed frog, Hyperolius spinigularis. Oikos 110 (2): 241-252

Walker JA (1997) Ecological morphology of lacustrine threespine stickleback Gasterosteus aculeatus L. (Gasterosteidae) body shape. Biological Journal of the Linnean Society 61 (1): 3-50

Walker JA, Bell MA (2000) Net evolutionary trajectories of body shape evolution within a microgeographic radiation of threespine sticklebacks (Gasterosteus aculeatus). Journal of Zoology 252: 293-302

Walker JA, Ghalambor CK, Griset OL, McKenney D, Reznick DN (2005) Do faster starts increase the probability of evading predators? Functional Ecology 19 (5): 808-815

Wallace AR (1879) The protective colours of animals. In Brown R (ed) Science for all. Cassell, Petter, Galpin \& Co., London 128-137

Warkentin KM (1995) Adaptive plasticity in hatching age: a response to predation risk trade-offs. Proceedings of the National Academy of Sciences of the United States of America 92 (8): 3507-3510

Waters DA (2003) Bats and moths: what is there left to learn? Physiological Entomology 28(4): 237-250

Webb PW (1984) Body form, locomotion, and foraging in aquatic vertebrates. American Zoologist 24: 107-120

Webb PW (1986) Locomotion and predator-prey relationships. In Lauder GV, Feder ME (eds) Predator-Prey Relationships. University of Chicago Press, Chicago 24-41 
Wellborn GA, Skelly DK, Werner EE (1996) Mechanisms creating community structure across a freshwater habitat gradient. Annual Review of Ecology and Systematics 27: 337-363.

Welty JC (1934) Experiments in group behavior of fishes. Physiological Zoology 7: $85-128$

Werner EE, Anholt BR (1993) Ecological consequences of the trade-off between growth and mortality rates mediated by foraging activity. American Naturalist 142 (2): $242-272$

West-Eberhard MJ (1989) Phenotypic plasticity and the origins of diversity. Annual Review of Ecology and Systematics 20: 249-278

West-Eberhard MJ (2003) Developmental plasticity and evolution. Oxford University Press, Oxford

Wiklund C, Tullberg BS (2004) Seasonal polyphenism and leaf mimicry in the comma butterfly. Animal Behaviour 68 (3): 621-627

Wilbur HM (1980) Complex Life Cycles. Annual Review of Ecology and Systematics 11: 67-93

Will U (1986) Mauthner neurons survive metamorphosis in anurans: a comparative study HRP study on the cytoarchitecture of the Mauthner neuron in amphibians. Journal of Comparative Neurology 244: 111-120

Williams GC (1966) Adaptation and natural selection. Princeton University of Press, Princeton

Wilson RS, James RS, Van Damme R (2002) Trade-offs between speed and endurance in the frog Xenopus laevis: a multi-level approach. Journal of Experimental Biology 205 (8): 1145-1152

Worthington EB (1940) Geographical differentiation in freshwaters with special reference to fish. In Huxley J (ed The new systematics. Oxford University Press, Oxford 287-303

Yack JE, Fullard JH (2000) Ultrasonic hearing in nocturnal butterflies. Nature 403 (6767): 265-266

Zaret TM (1980) Predation and freshwater communities. Yale University Press, New Haven 